Cómo citar este artículo / How to cite this article: Robles Moreno, J., Fenoll Cascales, J. y García Cano, J. M. (2021). Un nuevo vaso singular de Coimbra del Barranco Ancho (Jumilla, Murcia): lobos y rituales en el mundo ibérico. Lucentum, XL, 129-146. https://doi.org/10.14198/LVCENTVM.18416

\title{
UN NUEVO VASO SINGULAR DE COIMBRA DEL BARRANCO ANCHO (JUMILLA, MURCIA): LOBOS Y RITUALES EN EL MUNDO IBÉRICO
}

\author{
A NEW SINGULAR VASE FROM COIMBRA DEL BARRANCO ANCHO (JUMILLA, MURCIA): WOLVES \\ AND RITUALS IN THE IBERIAN CULTURE
}

\author{
JESÚS ROBLES MORENO \\ Universidad Autónoma de Madrid, España \\ jesus.robles@uam.es \\ https://orcid.org/0000-0002-5276-1974 \\ JOSÉ FENOLL CASCALES \\ Universidad de Murcia, España \\ jose.fenollc@um.es \\ https://orcid.org/0000-0002-4668-3471 \\ JOSÉ MIGUEL GARCÍA CANO \\ Museo de la Universidad de Murcia, España \\ jmgc@um.es \\ https://orcid.org/0000-0002-1371-7487
}

Recepción: 15/12/2020

Aceptación: 12/04/2021

\section{Resumen}

En este artículo se presenta un vaso cerámico calado descubierto en las excavaciones de la puerta oriental del poblado ibérico contestano de Coimbra del Barranco Ancho (Jumilla, Murcia). La pieza, que por contexto arqueológico se data en el siglo III a. C., se cataloga como un «vaso singular» por su excelente factura y sobre todo por mostrar en cada una de sus patas un prótomo de lobo modelado, representado con gran detalle. Esta circunstancia se da en otras tipologías cerámicas, pero hasta la fecha no se había documentado en un vaso calado. Considerando el papel simbólico de este animal en la cultura íbera y su relación con la aristocracia y sus ritos de tránsito e iniciación, se propone una función ritual para el recipiente, que por sus características pudo servir como brasero o quemaperfumes en esas ceremonias.

Palabras clave. Cerámica; cultura íbera; lobo; Coimbra del Barranco Ancho; ritual.

\begin{abstract}
In this paper we present a fretworked ceramic vase which was discovered in the excavations of the Eastern gate at the Contestanian-Iberian site of Coimbra del Barranco Ancho (Jumilla, Murcia). This piece of pottery, which can be dated back to the 3rd century $\mathrm{BC}$, is catalogued as «singular vase» due to its excellent manufacture and, especially, for presenting on each of its feet a modeled wolf head with great detail. This fact can be found in other typologies, but has never been documented on fretworked vases. Considering the symbolic role of this animal in the Iberian culture and its relation with aristocratic initiation and passage rites, a ritual function is proposed for this vessel which, according to its features, could have been used as a brazier or incense-burner in these ceremonies.
\end{abstract}

Key words. Pottery; Iberian culture; wolf; Coimbra del Barranco Ancho; ritual.

Financiación: Trabajo realizado en el marco del Grupo de Investigación E041-08 Arqueología Histórica y Patrimonio del Mediterráneo Occidental de la Universidad de Murcia y del Proyecto de I+D+i HAR-2017-82806-P: Ciudades y complejos aristocráticos ibéricos en la conquista romana de la Alta Andalucía. Nuevas perspectivas y programa de puesta en valor (Cerro de la Cruz y Cerro de la Merced, Córdoba), financiado por Proyectos de Excelencia del MINECO. Programa estatal de Fomento de la Investigación Científica y Técnica de Excelencia. También en el marco de una ayuda Formación Profesorado Universitario (FPU18-00735) del Ministerio de Ciencia, Innovación y Universidades. 


\section{EL YACIMIENTO DE COIMBRA DEL BA- RRANCO ANCHO (JUMILLA, MURCIA)}

El yacimiento de Coimbra del Barranco Ancho se localiza en el término municipal de Jumilla (Murcia) situándose exactamente a unos $4,50 \mathrm{~km}$ de su casco urbano. Físicamente se emplaza en las estribaciones septentrionales de la Sierra de Santa Ana, en un rellano comprendido entre la vertiente norte y oriental del Cerro del Maestre (García Cano, 1997: 21) (Fig. 1). Esto le otorga una excelente posición de control sobre las vías de comunicación como son la Rambla del Judío, cuyo curso permite el acceso a la Vega del Segura, y también el corredor del Pinoso que articula las comunicaciones desde el eje Hellín-Minateda hasta el Vinalopó. De esta manera se puede comprender que, además de la agricultura desarrollada en las tierras que circundan el yacimiento, el comercio fue una de sus principales vías económicas y de desarrollo (García Cano, 1997: 23).

Coimbra del Barranco Ancho está conformado por cinco espacios diferentes: un poblado amurallado, tres necrópolis de incineración y un santuario. Es por tanto un conjunto ibérico similar a los que encontramos en otros puntos de Murcia como Verdolay (Comino, 2015: 265) o El Cigarralejo (Mula, Murcia) (Cuadrado, 1987), constituidos por un oppidum al que se asocian un lugar de culto y uno o varios espacios funerarios.

El conocimiento científico de este yacimiento se remonta a los años 70 del pasado siglo cuando la añorada Dra. Muñoz Amilibia dirigió las excavaciones en la parte oriental del poblado (1977-1979, 19811984) e inició los trabajos en la necrópolis de «El Poblado» (1980-1983, 1992-1995) y la de «de La Senda» (1985-1987), continuados en la dirección posteriormente por García Cano (García Cano y Page del Pozo, 2007). Se realizaron además prospecciones superficiales y una excavación de urgencia en el santuario, descubierto en 1978 (García Cano et al., 1991-1992; García Cano et al., 1997). Desde entonces, los trabajos de investigación no han cesado en Coimbra del Barranco Ancho y en la actualidad, se encuentran en la fase final de cumplimiento de los objetivos establecidos en el Plan Director de 2015 (García Cano et al., 2016a).

Algunos de los avances de estas últimas campañas han sido ya adelantados en otros trabajos como es el caso del catálogo de la exposición sobre la Casa M (Gallardo et al., 2017) o de este artículo. Sin embargo, a falta del estudio y publicación de los resultados finales, se puede concluir que este enclave cuenta con una ocupación constatada desde el siglo IV a. C. hasta inicios del siglo II a. C. cuando, en el contexto de la Segunda Guerra Púnica, es destruido y abandonado (Gallardo et al., 2017: 13).

Abarca una extensión total aproximada de 5 hectáreas, viéndose fortificado por la protección natural que ofrece el terreno, así como por tramos amurallados documentados en el oeste del yacimiento, donde se ubica el único acceso al poblado conocido hasta la fecha. En el espacio intramuros, el urbanismo se distribuye en una serie de aterrazamientos, habiéndose
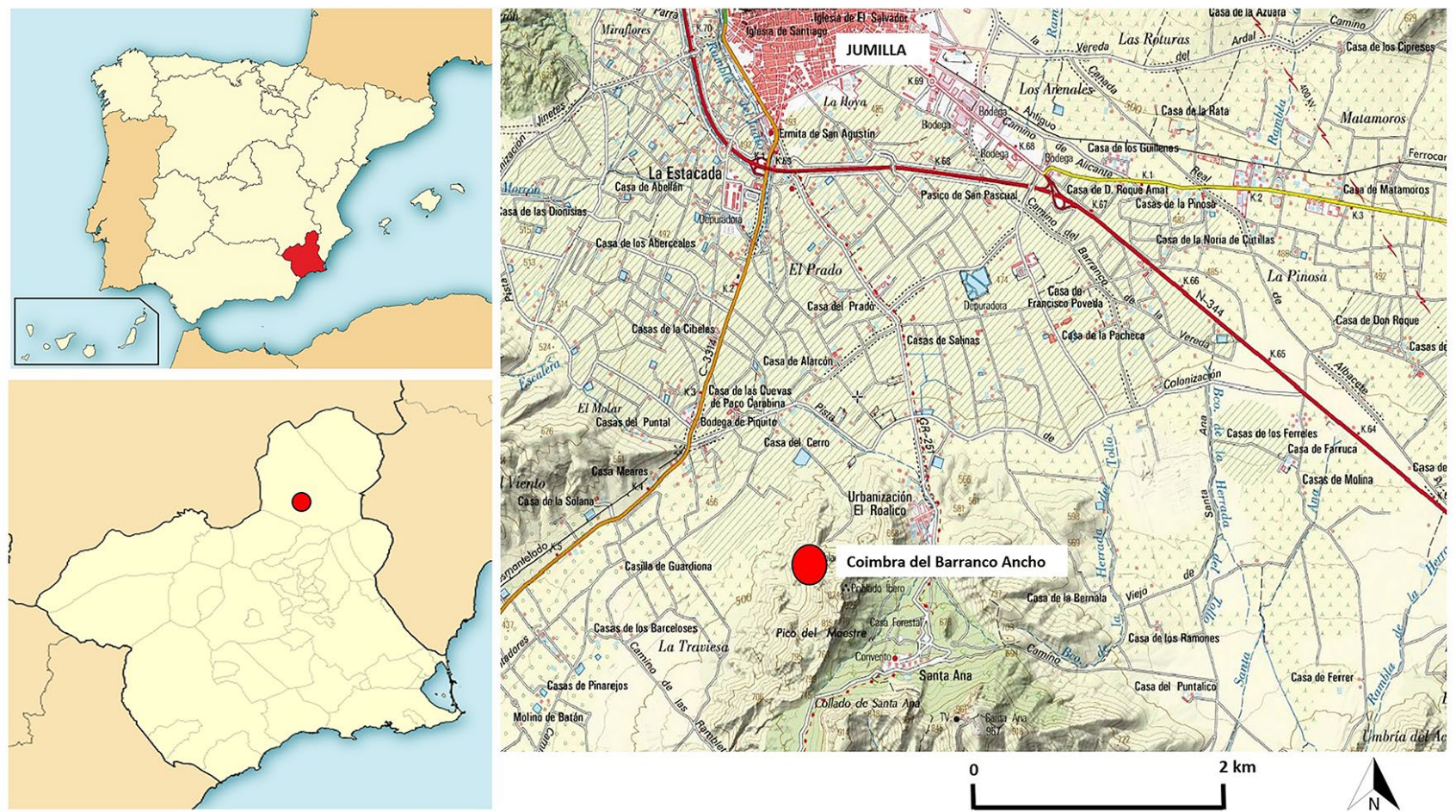

Figura 1: Ubicación del yacimiento de Coimbra del Barranco Ancho (Jumilla, Murcia). (Realización propia sobre base cartográfica del IGN) 
excavado en la actualidad sólo el más inmediato al conjunto de acceso oriental donde se ha documentado hasta un total de diez viviendas, habitualmente de un solo espacio, aunque hay otras que resultan mucho más complejas, como la «casa M» (Gallardo et al., 2017).

Sobre las necrópolis de incineración no vamos a insistir aquí, ya que estas han sido tratadas en extensas monografías (García Cano, 1997; García Cano et al., 2008). Bastará con señalar que las casi 300 sepulturas aquí halladas cubren una cronología que abarca desde comienzos del IV a. C. a los primeros años del II a. C. Finalmente, con respecto al santuario, localizado a 350 $m$ de la necrópolis de La Senda, cabe decir que hasta la fecha no se han documentado estructuras, más allá de favissas que contenían fragmentos cerámicos, pebeteros y máscaras de plata en miniatura (García Cano et al., 1991-1992; 1997; Adroher, 2018).

\section{EL VASO: DESCRIPCIÓN, PARALELOS Y PROPUESTA DE CRONOLOGÍA}

En este artículo se presenta un recipiente cerámico hallado en las excavaciones de este yacimiento que, por sus características, bien podría englobarse en la definición de «vaso singular ibérico» (Olmos, 1987; Uroz Rodríguez, 2013: 52), ya que resulta un ejemplar único hasta la fecha y por ende, merecedor de un trabajo monográfico. Es preciso señalar que esta pieza está incompleta, si bien se ha podido reconstruir aproximadamente un $75 \%$ de la misma gracias a los dos fragmentos conservados. El primero de ellos conserva el perfil completo del recipiente, lo que ha permitido conocer sus características formales y estudiarlo en profundidad (Fig. 2). El segundo en cambio corresponde a una de las patas en las que se conserva íntegramente uno de los apliques de lobo (Fig. 3).
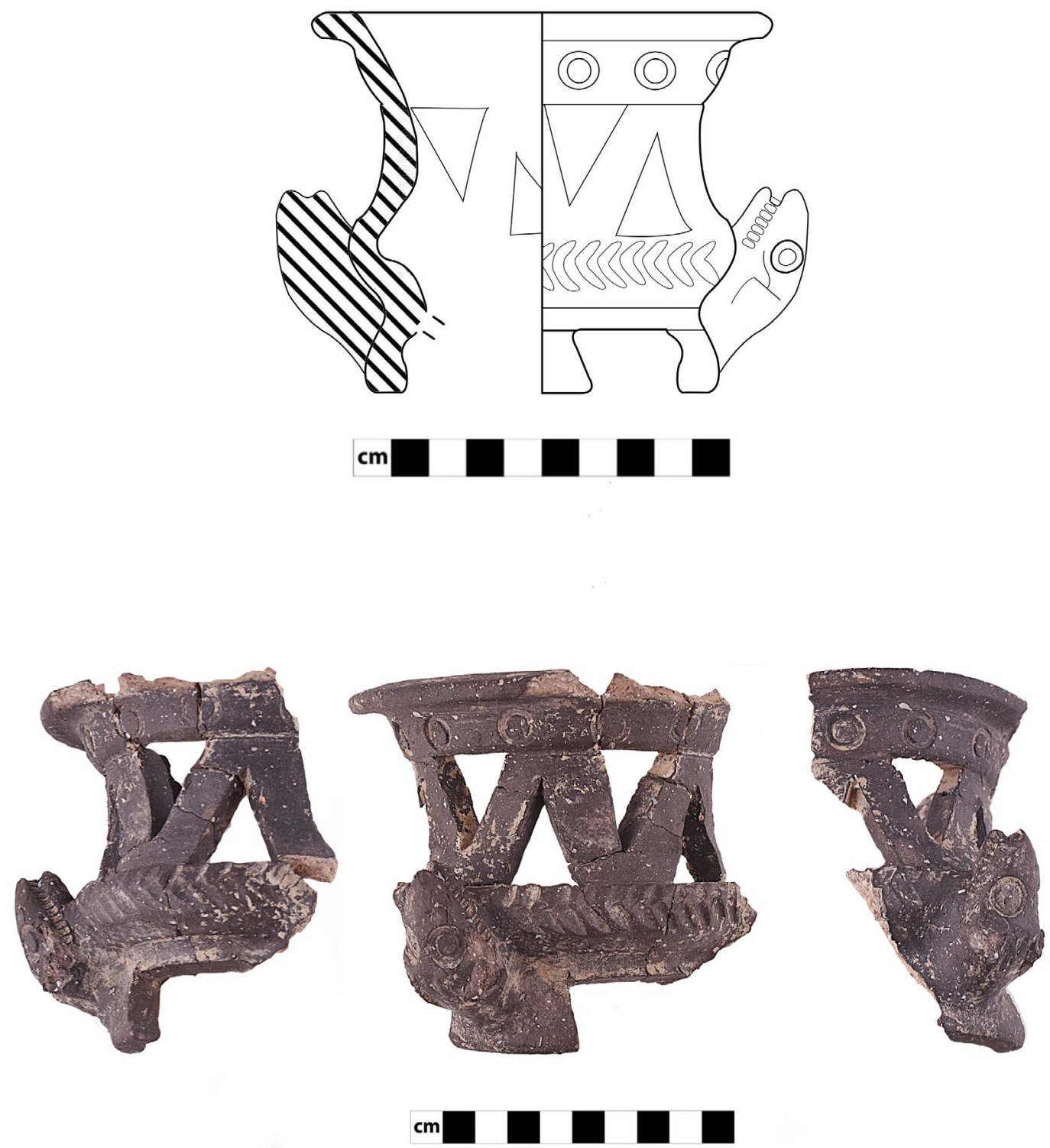

Figura 2: Varias vistas del perfil conservado y dibujo del desarrollo del vaso a partir del primer fragmento conservado. (Fotografía: Miguel Martínez Sánchez) 

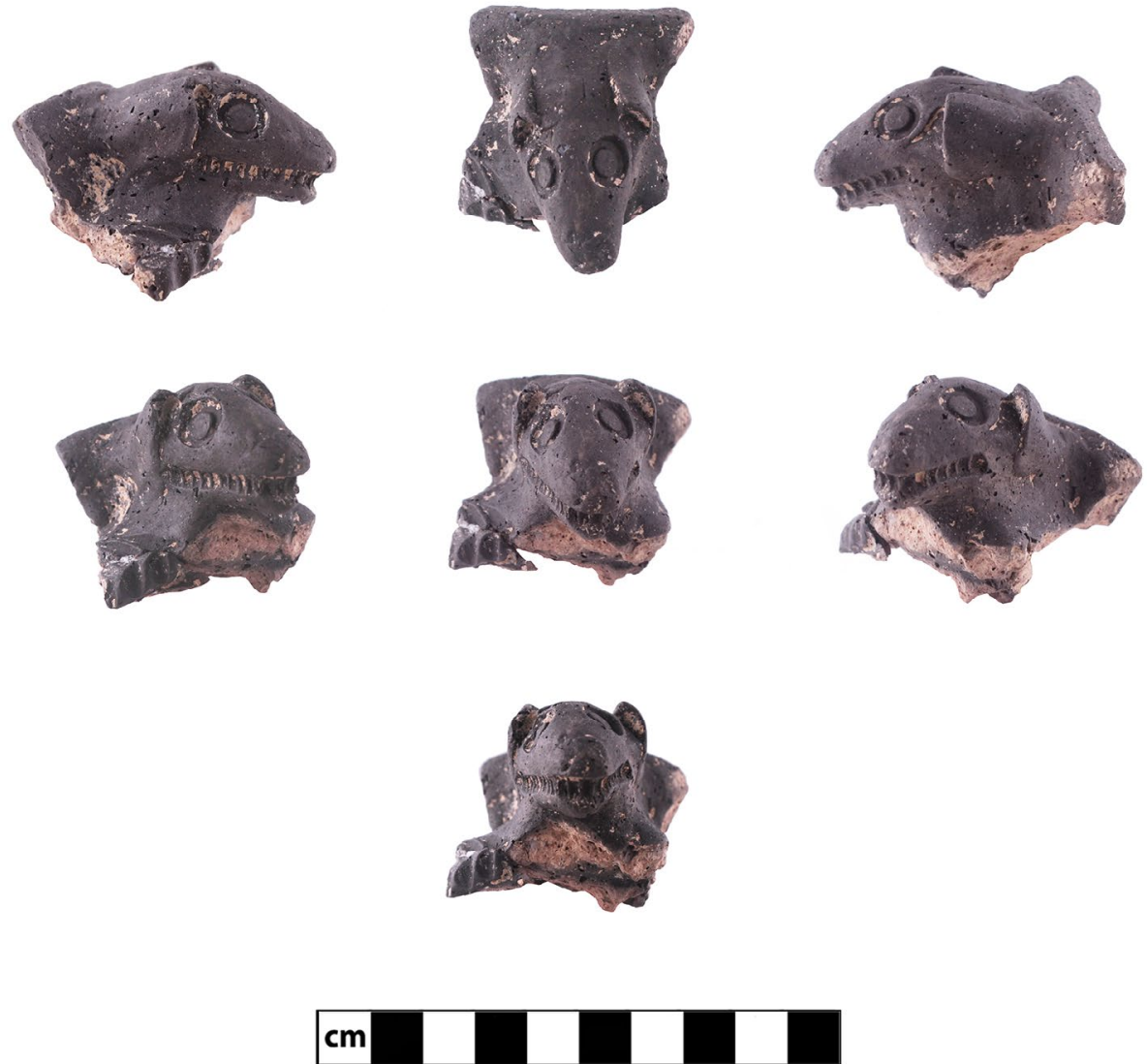

Figura 3: Varias vistas de uno de los prótomos de lobo del vaso, correspondiente al segundo fragmento del vaso. Obsérvese el detalle con el que se marcan los dientes, orejas y ojos. (Fotografía: Autores)

Se trata pues de un vaso calado de reducido tamaño, ya que dispone de una altura de $10 \mathrm{~cm}$ y un diámetro de $10 \mathrm{~cm}$ en el borde y $9 \mathrm{~cm}$ en su fondo. Presenta un cuerpo caliciforme con borde exvasado al exterior, su parte central se encuentra calada mediante una serie de triángulos de buen acabado y cuidada factura, ya que mantienen una altura isométrica de $2,50 \mathrm{~cm}$ y alternan su orientación, originando un friso que recuerda al motivo geométrico conocido como «dientes de lobo». Por encima de estos triángulos calados encontramos un registro de círculos realizados mediante impresión y por debajo de los mismos, sobre la marcada carena de la parte inferior del vaso, que es casi un baquetón, aparece también un friso de bandas con motivos en forma de $\mathrm{V}$ en posición horizontal, realizado mediante impresión.

El fondo del vaso se ha perdido por completo y sólo se intuye el arranque del mismo en la superficie interna, arranque que indica un posible aspecto umbilicado. En cualquier caso, este no constituye el punto de apoyo del vaso, sino que esa función la realizan tres patas. Sólo se conservan dos de ellas aunque si se tienen en cuenta los paralelos y la distribución de las mismas en el diámetro de la pieza es muy probable que se tratase de un vaso trípode. Es en estas patas precisamente donde aparece el rasgo más distintivo de la pieza, pues de cada una nace un prótomo de lobo que se orienta hacia arriba, es decir, con el hocico hacia el borde del vaso.
Estas cabezas, de $5 \mathrm{~cm}$ de altura máxima, presentan una morfología apuntada, con un hocico alargado en el que se pueden ver las fauces, constituidas por 19 dientes en cada ejemplar que se han realizado mediante impresión. Otro detalle reseñable de estos prótomos, son las puntiagudas orejas que se levantan en el tercio distal de la cabeza, especialmente visibles en el segundo fragmento por su estado de conservación (Fig. $3)$. También se han representado los ojos, concebidos desde una perspectiva cenital y realizados mediante impresión con la misma estampilla con la que se realizó el friso de círculos ubicado bajo el labio del recipiente. Las fauces entreabiertas, las orejas puntiagudas y los grandes ojos son, como veremos a continuación, rasgos inherentes a la figura del lobo en el mundo ibérico y, a pesar del esquematismo, permiten una segura adscripción faunística de estos prótomos.

Por último, cabe señalar que el vaso está realizado a torno, en pasta característica de la vajilla doméstica o de cocina que en este caso está muy bien depurada y presenta desgrasantes micáceos bastante homogéneos, de tamaño medio-grueso que oscila entre 1-1,50 mm. $\mathrm{Su}$ color, como se puede observar, es ocre anaranjado en el núcleo aunque la cocción reductora y la continua exposición al fuego que sufrirían estos vasos ha ennegrecido por completo su superficie. Al tacto es liso tanto al interior como al exterior de la pieza. 


\subsection{Paralelos: El lobo en los vasos zoomorfos IBÉRICOS}

No resulta novedoso en absoluto señalar que uno de los rasgos más característicos y sobradamente abordados de la cerámica ibérica son las representaciones zoomorfas que esta incluye, ya sea en forma de motivos pintados o a través del modelado del vaso o una parte del mismo. Si bien esto último se refiere en gran parte a los askoi zoomorfos, recipientes plásticos para aceites y perfumes que adquieren la forma completa del animal, también es preciso hablar de otros que, como aquí ocurre, no son plásticos en su totalidad sino que la representación zoomorfa se reduce a una parte del vaso. Esto es lo que García Cano y Page (2004: 168) denominan «apliques» pues parecen derivar, en origen, de imitaciones de recipientes metálicos. Existen prótomos de varias especies así representados, como son los leones del depósito votivo del Amarejo (Bonete, Albacete) (Broncano, 1989), carneros (Rafel Fontanals et al., 2018), bóvidos e incluso rostros humanos (García Cano y Page, 2004: 70-71 con bibliografía).

Centrándonos ya en las representaciones de prótomos o cabezas de lobo que pueden servir como paralelos de la pieza aquí estudiada, el más interesante es el kernos hallado en la tumba 15 de la necrópolis ibérica de Lorca (Cárceles et al., 2008; García Cano et al., 2016b) (Fig. 4), datable entre finales del siglo V a. C. e inicios del IV a. C. Este tipo de recipiente, el kernos, tradicionalmente se relaciona con la preparación de ofrendas líquidas, si bien en este caso se ha convertido en la urna funeraria de dicha sepultura, pues las cenizas del difunto se encontraban en uno de los kotilyskoi. Estos son tres opérculos caliciformes que, a diferencia de lo que ocurre habitualmente en los kernoi, no se conectan mediante canales huecos, sino que son macizos de modo que no permiten la mezcla de líquidos, que es la función del kernos. De esos canales hacia abajo penden volutas modeladas y en la parte central de los mismos aparecen los prótomos de lobo. Aunque sus rasgos son similares a las cabezas del vaso que se estudia, existen algunas diferencias, ya que presentan una morfología ligeramente más apuntada, se indican los ollares mediante dos pequeños orificios incisos y las fauces aparecen abiertas.

Como paralelo directo del kernos de Lorca, por su factura y características, y por tanto, paralelo también para la pieza aquí estudiada, deben citarse dos cabezas de cánidos, muy posiblemente lobos, halladas sin contexto en el Santuario de la Luz (Comino, 2015: 468470). Estas presentan un largo cuello y, a pesar de que han perdido las orejas, se aprecian los rasgos característicos de las representaciones de este animal que ya se han comentado, destacando en este caso los grandes ojos elaborados con dos círculos concéntricos que recuerdan a la pieza de Coimbra. También sin orejas y apenas detallada es la cabeza que aparece modelada en la parte inferior del «vaso de la diosa» de Libisosa (Lezuza, Albacete), interpretada igualmente como un lobo (Uroz Rodríguez y Uroz Sáez, 2016: 286; Uroz Rodríguez, 2018: 138).

Otro caso reseñable corresponde a un fragmento, posible pico vertedor, procedente de El Monastil (Elda, Alicante) (Uroz Rodríguez, 2009: 76) en el que se representa un prótomo de este animal con algo más de detalle, ya que se aprecian claramente las orejas levantadas y puntiagudas, las fauces marcadas y los ojos ligeramente almendrados concebidos desde una perspectiva cenital.

Finalmente cabe citar una tinajilla adscribible al estilo tradicionalmente denominado «Oliva-Liria» que se conserva en la sede de Granada de la Fundación

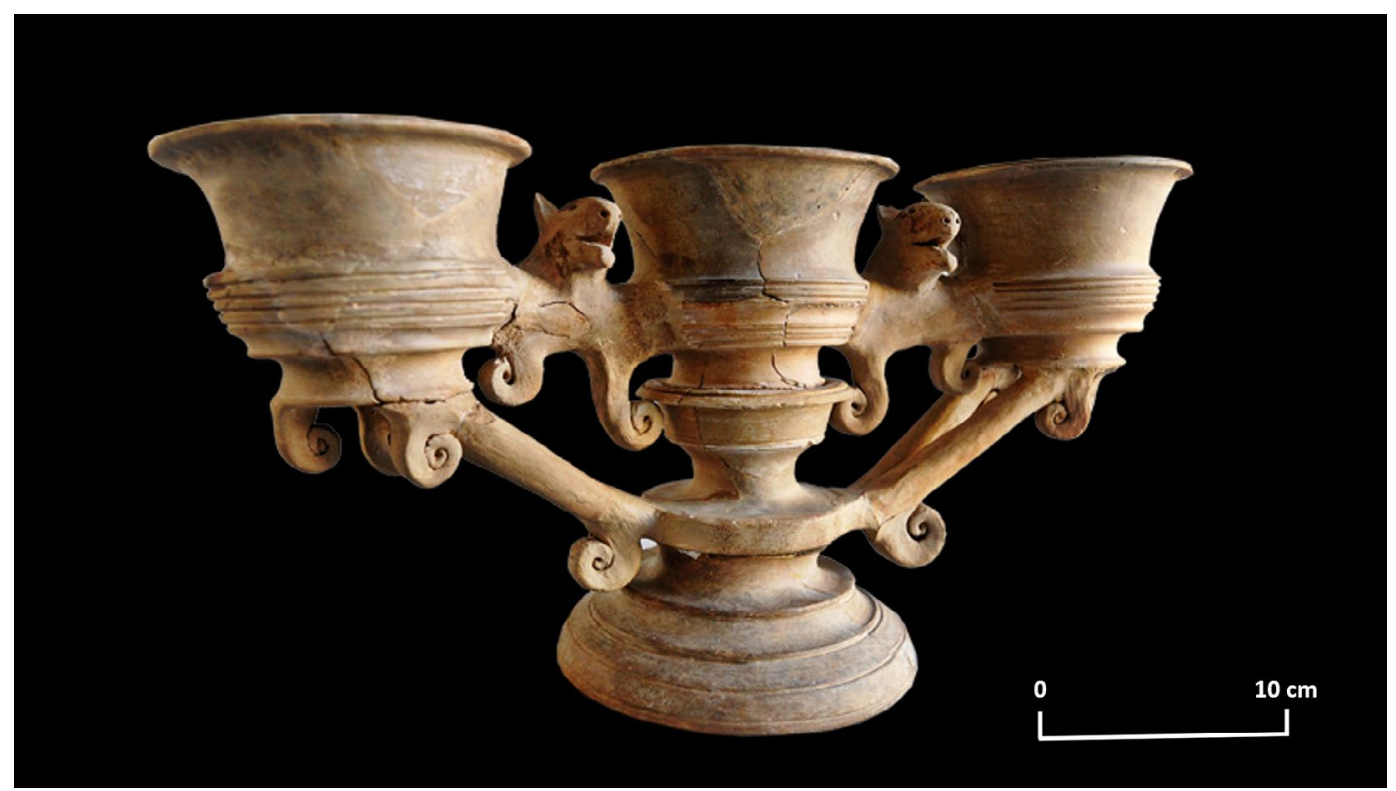

Figura 4: Kernos de la tumba 15 de Lorca, obsérvense los prótomos de lobo entre los kotilyskoi. (Fotografía: Museo Arqueológico de Lorca) 
Carlos Ballesta (Ferrer y Escrivà, 2018). Aquí los prótomos de lobo aparecen como apliques que rematan la parte superior de cada una de las dos asas, en el punto donde se unen con el labio de la pieza (Ferrer y Escrivá, 2018: fig. 1). Morfológicamente presentan características análogas a las que figuran en los otros ejemplares comentados, con la particularidad de que en este caso las orejas no aparecen levantadas, sino plegadas hacia atrás, sobre la cabeza del animal.

Este paralelo resulta algo problemático, ya que hasta 2018 solo se conocía por un dibujo, conservado en el Museo de Liria, de una supuesta pieza verdadera, representación gráfica que sirvió como inspiración para realizar al menos dos tinajillas falsas (Ferrer y Escrivá, 2013; Bonet y Mata, 2017). Recientemente Ferrer y Escrivá (2018) han señalado que el vaso de la Fundación Carlos Ballesta es la fuente original de dicho dibujo y que se trata de una pieza auténtica, algo que parece altamente probable desde el análisis epigráfico de las inscripciones que contiene (Ferrer y Escrivá, 2013; 2018). Sin embargo, la falta de contexto, el hecho de que el vaso haya sido falsificado en numerosas ocasiones y sobre todo, el contenido y estilo de su decoración pintada suscitan aún algunas dudas sobre su autenticidad, que se resolverán mediante las pertinentes analíticas. En cualquier caso, sea o no auténtica la pieza conservada en Granada, lo cierto es que el dibujo en el que se basaron las falsificaciones parece indicar la existencia de una tinajilla real que incluía esos prótomos de lobo.

\subsection{El CONTEXTO DEL HALLAZGO Y PROPUESTA DE CRO- NOLOGÍA}

Afortunadamente, y a diferencia de algunos de los paralelos citados, este vaso puede ser contextualizado estratigráficamente, ya que su hallazgo se produjo en el marco de las campañas de excavación de Coimbra del Barranco Ancho de 2017 y $2019^{1}$. Más en concreto se halló en el denominado «Sector Puerta» (Fig. 5) que se corresponde con las estructuras que integran el acceso fortificado al poblado en la parte oriental del mismo.

Aunque esta puerta oriental se encuentra actualmente en fase de estudio, se puede adelantar que cuenta con dos fases constructivas diferenciadas, remontándose la primera de ellas al siglo IV a. C. Es esta la peor conocida por las reformas posteriores, aunque parece corresponderse con una puerta carretera con un vano de 3,20 $\mathrm{m}$ de anchura, flanqueada en su lado izquierdo por una sola torre cuadrangular de aproximadamente 2,90 $\mathrm{m}$ de lado. Posteriormente sufrió una serie de reformas hacia mediados del siglo III a. C. o

1. Esta diferencia entre campañas obedece a la distancia a la que se hallaron los fragmentos que provocó que uno de ellos, el segundo quedase fuera de los límites del corte de 2017, no encontrándose hasta 2019, momento en el que este se amplió. en los primeros años de la segunda mitad de esa centuria, con anterioridad en cualquier caso a la Segunda Guerra Púnica. En estos momentos, esa torre del siglo IV a. C. se amplía notablemente, alcanzando 5,70 x $4,45 \mathrm{~m}$ de lado y se incorporan nuevas estructuras que dan estabilidad a la puerta y que forman parte del sistema defensivo. Esto provoca una reducción de su vano, que pasa a tener ahora 2,80 m de luz (García Cano, 2015: 58-59).

Si bien se conoce la secuencia constructiva general de la puerta, así como la de las estructuras que integran la torre y el espacio de paso de la misma, aún quedan algunas cuestiones por dirimir para las que será necesario continuar excavando. La principal de ellas es conocer al completo la parte septentrional de este sector para confirmar o descartar la existencia de una puerta lateral de menor tamaño, sobre la que ya hay algunos indicios. Otra cuestión es conocer la adscripción cronológica de la torre o bastión que se sitúa al otro lado de este complejo, aún no excavada pero visible en superficie, para saber si forma parte del acceso del siglo IV a. C. o, más probablemente, de las de mediados del III a. C.

En cualquier caso, es seguro que estas estructuras cayeron al producirse el incendio, destrucción y abandono del poblado a finales del siglo III a. C. o comienzos del II a. C. Este proceso queda reflejado en la estratigrafía del pasillo de acceso de la puerta, el espacio entre las unidades murarias UC 10.104 y UC 10.105 (Fig. 6). Allí aparece en primer lugar una capa de tierra amarillenta y homogénea, muy dura y con alta presencia de grava que se corresponde con el firme o preparado de suelo de tierra apisonada que constituía la superficie de paso de la puerta en su fase de mediados del siglo III a. C. (UC 10.115).

Directamente sobre esta se encuentran dos estratos que pertenecen al derrumbe de las estructuras: en primer lugar se puede documentar la UE 10.111, una unidad formada por tierra marrón oscura con textura granulosa, baja compactación y presencia media-alta de ceniza en algunos puntos que se corresponde con el incendio y/o la descomposición de los elementos lígneos que conformaban la parte superior del acceso. La segunda unidad (10.102) corresponde a la caída de los muros de la torre y de las estructuras que integran el conjunto de acceso, ya que se trata de un estrato de gran potencia, muy alta compactación y color anaranjado, formado principalmente por la disolución de adobes, en el que se incluyen además algunos sillares pétreos.

Precisamente este vaso se halló en esa UE 10. 111, es decir, está situado directamente sobre el suelo de paso que corresponde a la puerta del siglo III a. C. (UC 10.115) y que queda sellado por el primero de los dos estratos de derrumbe que se produce a finales de dicha centuria, lo que ayuda a precisar bastante su cronología. Ahora bien, si este «efecto sepultura» provocado por la caída de las diversas construcciones y la disolución de las paredes de adobe ha permitido recuperar en el 


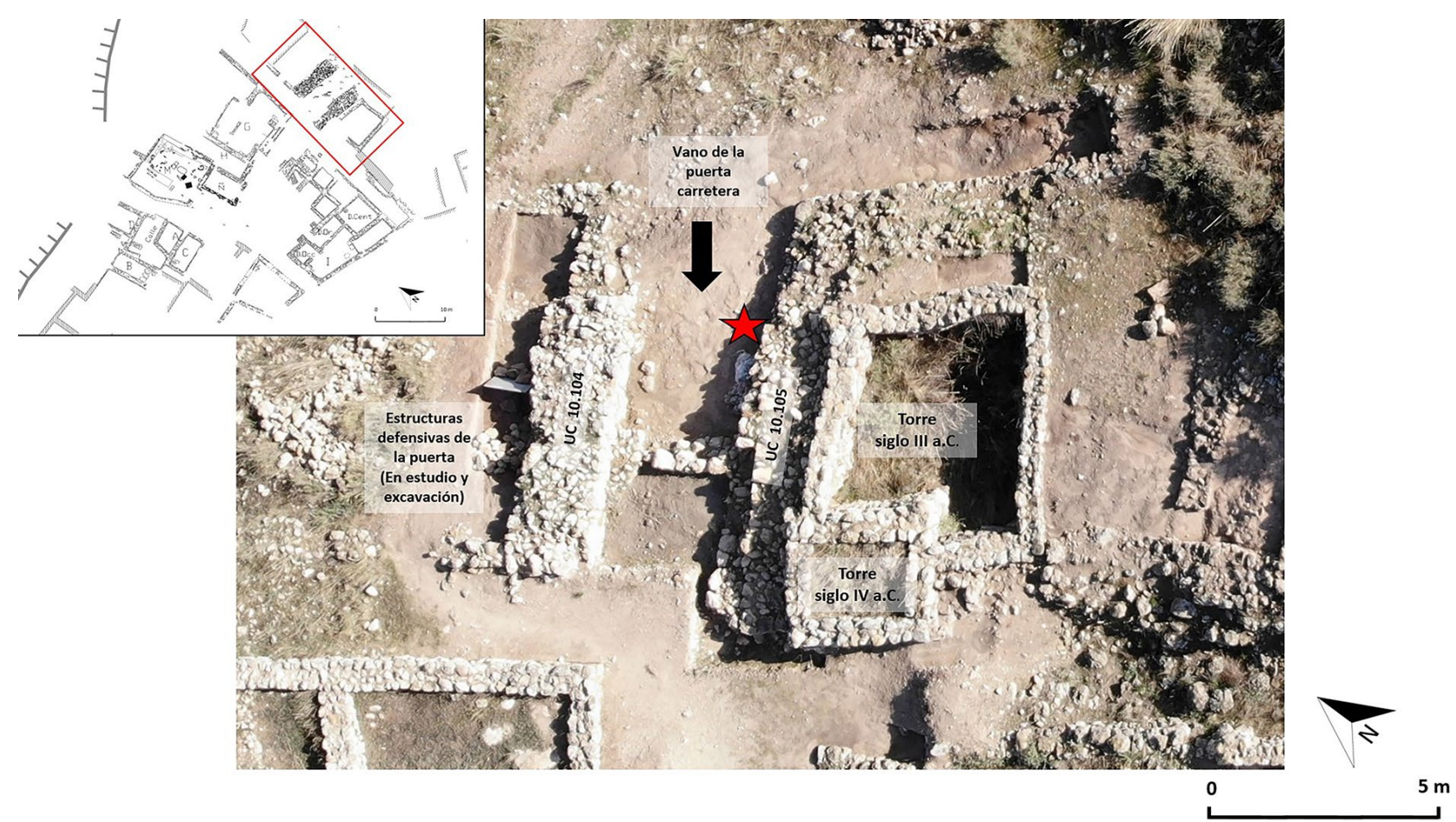

Figura 5: Estructuras que integran el conjunto de acceso oriental de Coimbra del Barranco Ancho. La estrella marca la ubicación exacta del hallazgo del vaso. (Fotografía: José Javier Martínez. Montaje: Autores)

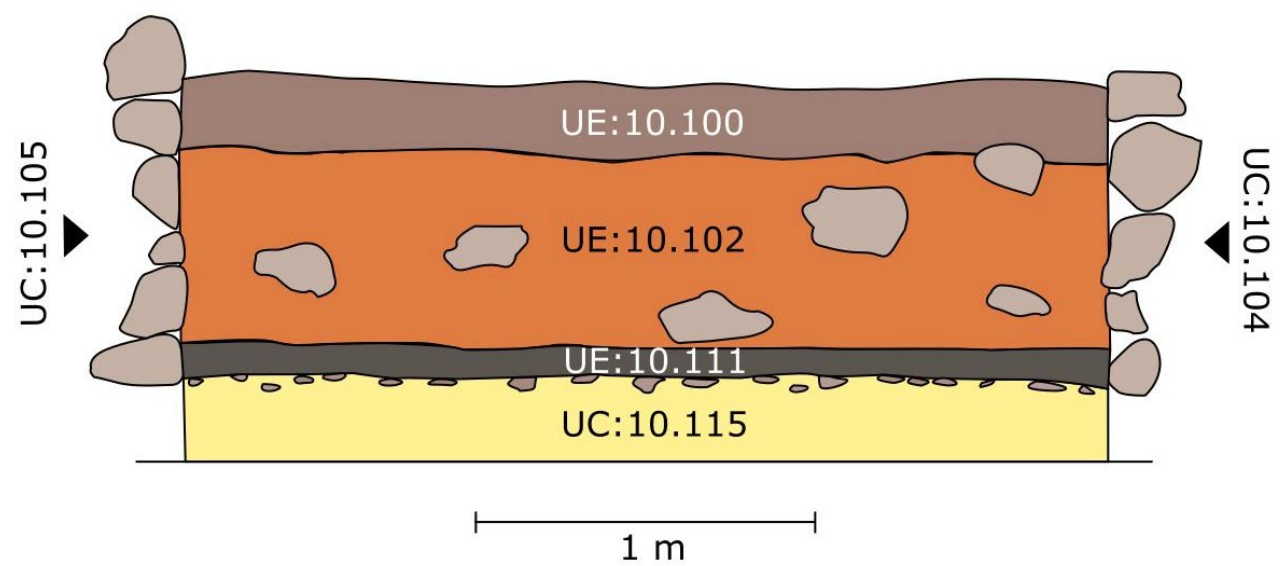

Figura 6: Dibujo del perfil arqueológico de la zona de paso de la puerta, entre las estructuras murarias 10.104 y 10.105. La unidad en la que apareció el vaso es U.E. 10.111 (Realización: Autores)

interior de las viviendas los ajuares domésticos y sus piezas completas (Gallardo et al., 2017), no ocurre lo mismo en este sector. Aquí aparece una abundante cantidad de fragmentos, generalmente bastante atomizados, que pertenecen a recipientes tanto de cerámica ibérica fina o de mesa - pintada y común-, como de almacenamiento y de cocina.

Entre los materiales cronológicamente diagnósticos que aquí se recogen (Fig. 7) ${ }^{2}$, estos apuntan la datación anteriormente comentada, destacando en primer lugar

2. Para un estudio completo de la puerta, su secuencia y los materiales hallados en las diversas unidades (algo que excedería un pequeño fragmento correspondiente al baquetón de una oinochoe estampillada (CBA-SP-183; Fig. 7: 1). Se trata de un tipo de producción muy concreto cuyo taller pudo estar en Coimbra del Barranco Ancho y que por sus contextos de aparición, no sólo en este poblado sino en otros como El Amarejo (Broncano y Blánquez, 1985: 209), se data hacia mediados del siglo III a. C. (García Cano, 1997: 163). Igualmente significativo es el hallazgo de una mano de mortero bitroncocónica (CBA-SP- 114; Fig. 7: 2), dado que

sin duda los límites de este trabajo), remitimos a García Cano et al., e.p. 


\section{SECTOR PUERTA}

U.E. 10111
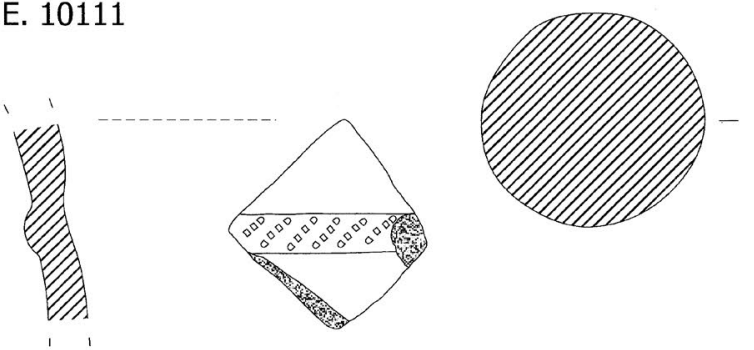

1-CBA-SP-183

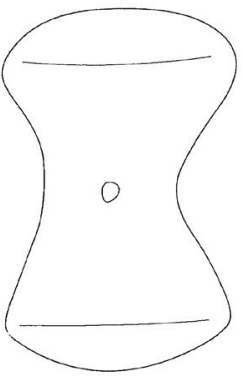

2-CBA-SP-114

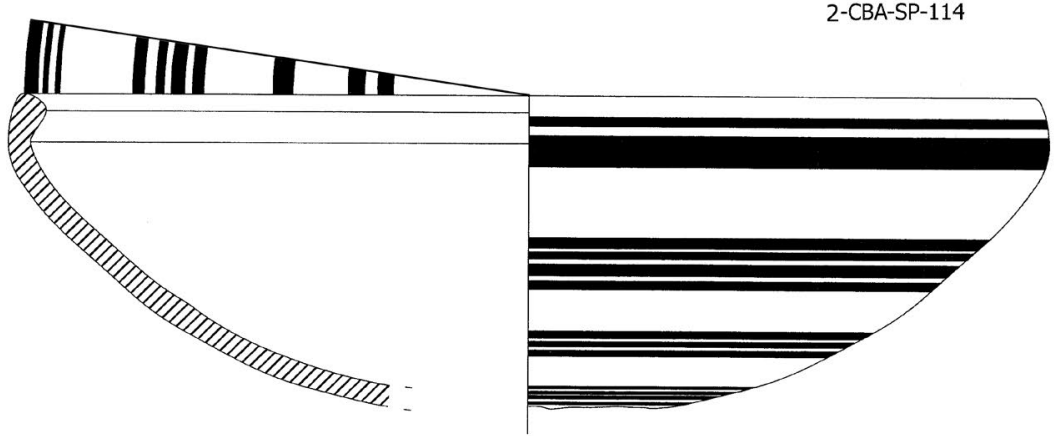

3-CBA-SP-276

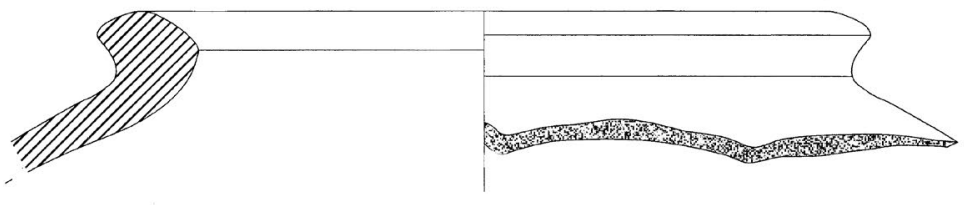

4-CBA-SP-196
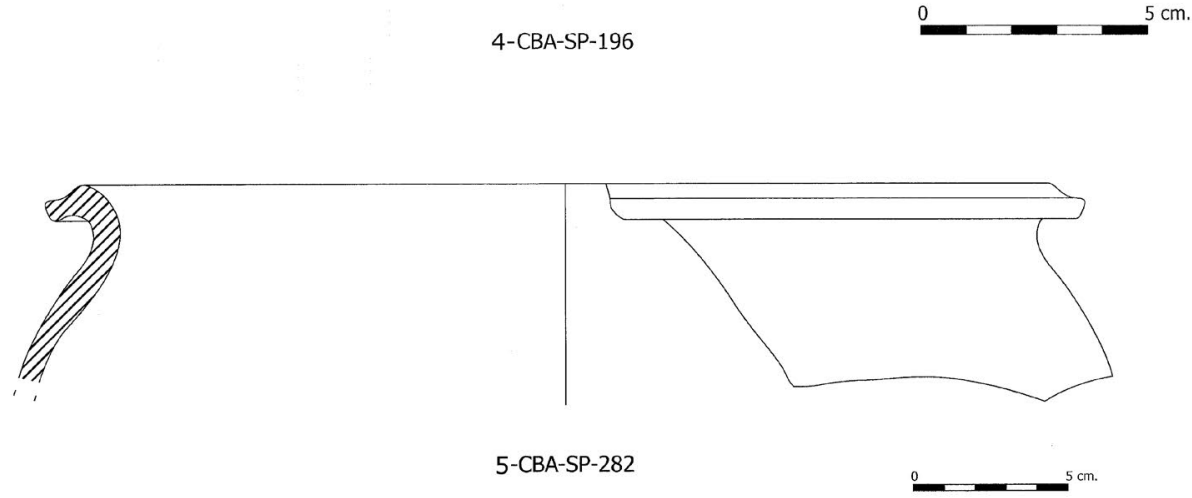

Figura 7: Materiales cronológicamente diagnósticos hallados en la unidad 10.111. 1- Fragmento de cuello de oinochoe de cerámica ibérica estampillada. 2- Macita o mano cerámica de mortero. 3- Plato de la forma 26, Tipo 1 Variante 2 de Coimbra de cerámica ibérica pintada. 4- Borde de Ánfora. 5- Borde de vaso globular (Dibujos: Eva María Martí Coves. Montaje: Autores)

estos ítems no aparecen en la Necrópolis de La Senda, que tiene una cronología del siglo IV a. C., pero sí en varias estancias del poblado y en la superficie de la necrópolis homónima, lo que corresponde a su última fase de utilización y permite ubicar estas piezas a finales del III a. C. o inicios del II a. C. (García Cano, 1997: 193). Estas mismas circunstancias de hallazgo ocurren en este yacimiento con las grandes ánforas (García Cano, 1997: 128), habiéndose documentado en esta UE 10.111 el borde de una de ellas (CBA-SP196; Fig. 7: 4).

Otros fragmentos interesantes de esta unidad son un borde de un gran vaso globular (CBA-SP-282, fig. 7: 5), producción que en Coimbra se data hacia el III a. C. (García Cano, 1997: 137), así como un plato de borde recto de la forma 26, Tipo 1, Variante 2 de Coimbra del Barranco Ancho (CBA-SP-276, fig. 7: 3) (García Cano, 1997: 176-177), tipología que en la Necrópolis 


\section{SECTOR PUERTA}

\section{U.E. 10111}
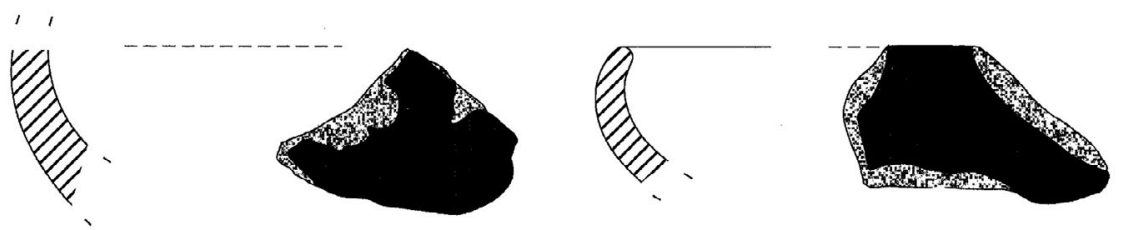

2-CBA-SP-271

1-CBA-SP-319

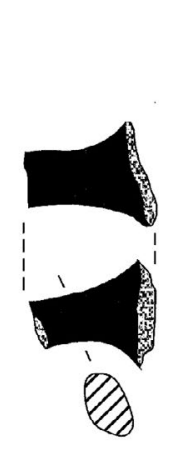

3-CBA-SP-182

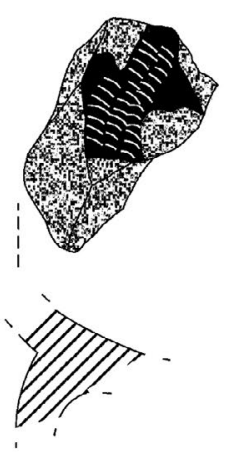

4-CBA-SP-120

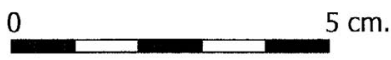

Figura 8: Fragmentos rodados de cerámica ática de barniz negro hallados en la unidad 10.111. (Dibujos: Eva María Martí Coves. Montaje: Autores)

del Poblado se extiende entre el 375 y el 200 a. C. Se documenta también en la última fase del oppidum, como es el ejemplar hallado en la casa M (Gallardo et al., 2017: 26-27, COI-M-85).

En definitiva y a pesar del estado fragmentario de los materiales se puede señalar que son análogos a los que aparecen en las unidades domésticas y permiten por tanto datar el estrato hacia el siglo III a. C., lo que está en plena consonancia con la evolución arquitectónica y la destrucción del poblado en general y de su puerta en particular. Ahora bien es cierto que en esta unidad existe material residual que parece indicar una datación más antigua, como son fragmentos de barniz rojo y sobre todo de cerámica ática de barniz negro (Fig. 8). No obstante, basta con echar un vistazo a los mismos para comprobar que se trata de fragmentos residuales, de pequeño tamaño y muy rodados. Estas perduraciones, así como la heterogeneidad y el estado fragmentario de los materiales recuperados en el «Sector Puerta», son producto de la naturaleza de este punto del yacimiento, cuyos contextos arqueológicos, como se ha visto, resultan totalmente diferentes de los que se pueden encontrar en el interior de las viviendas.

Estamos en este caso ante un ámbito de puerta urbana, una zona de tránsito continuo donde no existen amplias vajillas y ajuares al completo, sino que sería frecuente la acumulación de fragmentos que en muchas ocasiones rodaron desde varios puntos del poblado. Esto último cobra especial relevancia en el caso de Coimbra, si se tiene en cuenta la orografía y la distribución del urbanismo de este yacimiento, que convierten a esta puerta en el punto principal de evacuación de aguas de la parte oriental del poblado. Así pues, las escorrentías formadas arrastraban los sedimentos y restos cerámicos muy rodados que con frecuencia se documentan en sus calles, sobre todo en el espacio central situado inmediatamente tras este acceso.

Para finalizar con esta breve síntesis del registro material y a modo de comentario, pues se encuentran en fase de estudio y publicación, cabe señalar que en esta unidad estratigráfica, así como en otras unidades del conjunto de la puerta se han documentado más de 250 «fichas», tejuelos o recortes de cerámica (Fig. 9) que pudieron guardar relación con algún sistema de conteo (Castro, 1978). Es cierto que en varias ocasiones, estos materiales pudieron desempeñar un papel simbólico o ritual, ya que aparecen en depósitos votivos como el de la Bastida de Les Alcusses (VivesFerrándiz et al., 2015: 294), El Amarejo (Broncano, 1989: 106-109) o el de Granada (Moreno y Adroher, 2019: 77), sin embargo no creemos que este sea el 


\section{SECTOR PUERTA}

U.E. 10102

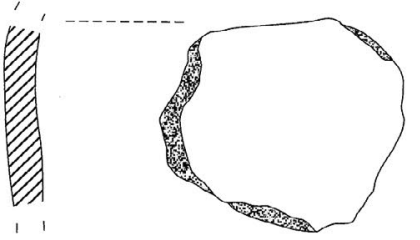

1-CBA-SP-70.1

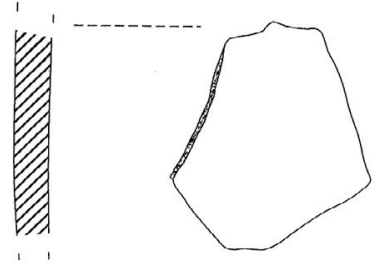

3-CBA-SP-70.3

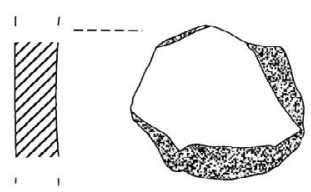

5-CBA-SP-70.5

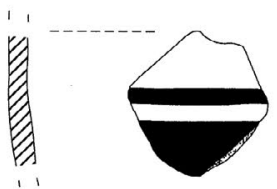

7-CBA-SP-70.7

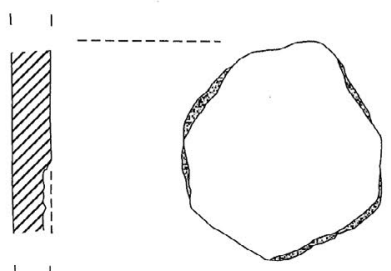

9-CBA-SP-115.1

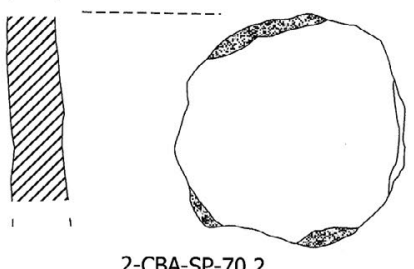

2-CBA-SP-70.2

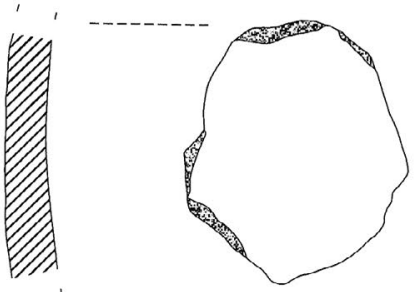

4-CBA-SP-70.4

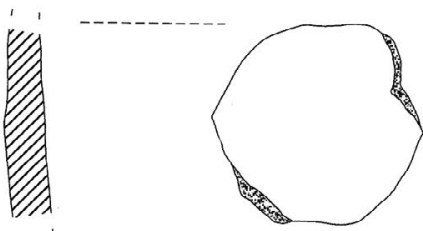

6-CBA-SP-70.6

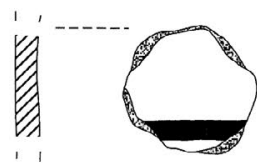

8-CBA-SP-70.8

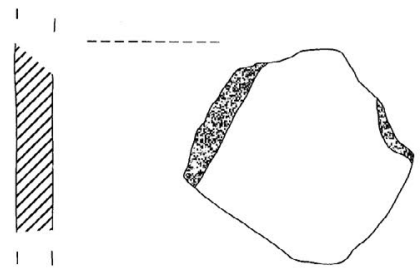

10-CBA-SP-115.2

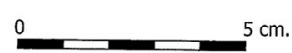

Figura 9: Conjunto de fichas o tejuelos de cerámica ibérica hallados en el contexto de la puerta, en este caso perteneciente a la unidad 10.111 (Dibujos: Eva María Martí Coves. Montaje: Autores)

caso, ya que hasta la fecha en el entorno de la puerta no se ha documentado depósito votivo de ningún tipo (vid. Apartado 4).

Además, estos elementos aparecen no sólo en varias unidades, como ya se ha dicho, sino también en varios puntos del conjunto de acceso, tanto en el espacio que corresponde al paso central como fuera de él. Es además un material que se documenta con bastante frecuencia en contextos domésticos de Coimbra del
Barranco $A_{n c h o}{ }^{3}$ : sin ir más lejos, la casa G, que es la más cercana a la puerta, cuenta con 120 ejemplares y

3. Así como en otros poblados ibéricos como son la Bastida (Fletcher et al., 1969: 270) o los 24 ejemplares documentados en el departamento 42 de Sant Miquel de Llíria (Bonet, 1995: 182 y 215$)$. 
en ese espacio central o calle del poblado que se ubica tras el acceso, son 69 los documentados.

En definitiva, en este caso la documentación estratigráfica es lo bastante fuerte para argumentar una datación del vaso hacia el siglo III a. C., ya que se encontraba sobre el pavimento de la puerta cuando las estructuras se derrumbaron a finales de esa centuria o comienzos de la siguiente, sellando así las piezas cerámicas -más bien los fragmentos- allí presentes. Existe una mínima posibilidad de que, al igual que los fragmentos de barniz rojo o de cerámica ática conservados aquí, sea un vaso de cronología anterior, quizá del siglo IV a. C., que se fragmentó y rodó durante décadas hasta quedar depositado en este sector del yacimiento. Aunque no se puede descartar totalmente esta opción, resulta menos plausible pues a pesar de que no se conserva completo, el vaso no está tan atomizado como los fragmentos referidos, ni tampoco su superficie está tan desgastada. Dentro del marco del siglo III a. C. es complicado ofrecer una fecha de creación exacta, pero está claro que su deposición acontece sobre un suelo o nivel de paso levantado a mediados de dicha centuria y queda sepultado por el derrumbe producido a finales de esta.

Además, esta tipología cerámica, los vasos calados o braserillos, se documentan en Coimbra durante el Ibérico Pleno (s. IV-III a. C.) (García Cano, 1997: 188; Molina et al., 1976: 63-64), habiéndose hallado varios de ellos en la Necrópolis de El Poblado, pero sobre todo -y dentro de la escasez del repertorio- en las viviendas, con una cronología por tanto análoga a la propuesta para este ejemplar. Son abundantes estos vasos en El Amarejo, donde se documentan desde el siglo IV a. C. al II a. C. (Broncano y Blázquez, 1985: 300) y se ha propuesto la existencia de un centro productor que pudo distribuirlos por el área (García Cano, 1997: 188), si bien ninguna de las piezas de dicho yacimiento ofrece características similares a este ejemplar. También están presentes en Los Villares (Caudete de las Fuentes, Valencia), donde figuran entre el siglo V a. C. y mediados del III a. C. (Pla, 1980; Mata, 1991: 193-195; Mata et al., 2019: 117).

En definitiva, como ya señalaba Mata (1991: 107) y más recientemente ha indicado Uroz Rodríguez (2012: 154-155 con bibliografía), parece ser que la presencia más acusada de estos vasos calados, que nunca llegarán a ser mayoritarios, ocurre en un momento avanzado del Ibérico Pleno. Esto explica su ausencia en yacimientos como La Bastida de Les Alcusses (Mogente, Valencia) y a la vez su presencia en otros como el Tossal de Sant Miquel (Liria,Valencia), Coimbra del Barranco Ancho, el Cerro de los Santos (Montealegre del Castillo, Albacete) (Sánchez Gómez, 2002: 172192) o Libisosa, prolongándose en este último enclave hasta el Ibérico Tardío (Uroz Rodríguez, 2012: 154155; Uroz Rodríguez y Uroz Sáez, 2014: 200).

Para concluir, a esos sólidos datos estratigráficos y también a los relacionados con la tipología cerámica se pueden añadir algunos indicios referidos a la representación del lobo, ya que precisamente prolifera en este Ibérico Pleno avanzado. Como han señalado Mata y Soria (2012: 75) las imágenes de cabezas o prótomos de lobo, con cierto valor heráldico o ceremonial, son numerosas en la cultura ibérica. Por poner algunos ejemplos de estas, datables en estas cronologías, se pueden citar el pectoral escultórico de La Alcudia, datado en el siglo IV a. C., varios ejemplares de fíbulas argénteas (Mata et al., 2013: 189) (vid. infr.) o de páteras metálicas como las de Tivissa (Tarragona) (s. III-II a. C.) o de Perotito (Santisteban del Puerto, Jaén) (Olmos y Rueda, 2015: 352 y ss. con bibliografía). Estos últimos casos resultan especialmente interesantes para nuestro estudio si se tiene en cuenta el comentario ya referido de García Cano y Page (2004: 168), quienes señalaban que los apliques modelados en cerámica imitan piezas metálicas (vid. supr.). En ese sentido, quizá la pieza que se estudia pudo haberse inspirado en esos apliques que presenta la vajilla helenística en plata que llega a nuestra península precisamente a partir del siglo III a. C.

Otro ejemplo interesante, aunque no se trata ya de un prótomo, es la tapadera de la caja funeraria de Villargordo, fechada en el siglo III a. C. (Chapa, 1979; 2015). En ella, el lobo es morfológicamente similar al aquí estudiado, pues presenta un hocico alargado y redondeado en su punta, con los ojos del animal concebidos para su observación desde una perspectiva cenital y las orejas apuntadas, situadas también en la parte trasera de la cabeza. Estas mismas características son las que figuran en la cabeza de un relieve de Osuna donde se representa un híbrido entre el lobo y el león (García Cano y Page, 1983). Además de todos estos casos, a los que se podrían añadir otros tantos en varios formatos y soportes (vid. infr.) conviene citar la proliferación de este animal, el carnassier-lobo (modelo iconográfico-significado), como uno de los motivos predilectos en la cerámica ibérica figurada del sureste desde el siglo III a. C., cuando aparecen ya en el Cabecico del Tesoro (Conde, 1990; Pérez Blasco, 2014: 400 y ss.), continuando durante el Ibérico Tardío, cuando están presentes, por ejemplo, en la cerámica ilicitana (Blanco Freijeiro, 1993; Tortosa, 2006: 153).

\section{EL LOBO: UN ANIMAL TOTÉMICO PARA LA CULTURA IBÉRICA}

En la cultura ibérica, las hibridaciones existentes y las variaciones de características que sobre cualquier soporte presentan las representaciones de leones, lobos y otros carnívoros, como por ejemplo los perros (Mata y Soria, 2012: 74; Mata, 2014: 126), han suscitado un amplio debate en cuanto a su adscripción a una especie u otra ${ }^{4}$. Incluso, en ocasiones estas imágenes reflejan

4. Para un repertorio de estas imágenes ambiguas o de difícil adscripción véase Mata y Soria (2012: 57-58). 
seres míticos o difíciles de identificar, como el que se esconde bajo el también complejo término «carnassier» (Uroz Rodríguez, 2007: 77 y ss.). En cambio, en el caso concreto del recipiente que nos ocupa, las orejas puntiagudas, las fauces abiertas con los dientes visibles y los grandes ojos permiten señalar que los prótomos aquí presentes representan al lobo. Esto se debe a que esas características mencionadas, como ya señaló Blanco Freijeiro (1993: 86), de acuerdo con las pioneras investigaciones de Obermaier y Heiss (1929), son rasgos propios y definitorios de este animal en la cultura ibérica. Se puede apreciar además que el artesano ha puesto énfasis en la representación detallada de los mismos, lo que refleja una voluntad de representar al lobo y que este fuese reconocido como tal.

El lobo es un animal con un carácter totémico común a numerosas culturas del Mediterráneo Antiguo (Fogliazza, 2020: 99-97). Es el caso, por citar un ejemplo, de Grecia, donde guarda una clara vinculación con Apolo y Zeus, recogida en los abundantes pasajes literarios estudiados por Richardson (1977) o más recientemente por Buxton (2013: 60-79) y Moore (2016). Esta asociación entre el lobo y la divinidad no es sólo propia del mundo clásico, sino que se repite en otras culturas, como puede ser la etrusca.

En esta última, el lobo se vincula a la figura de dioses ctónicos e infernales que se representan ataviados con la piel de este animal (Rupp, 2007: 48 y ss.), como se puede ver en la tomba dell' Orco (Tarquinia), tomba Galini (Orvieto) y en un sarcófago de Torre San Severo (Orvieto) (Rupp, 2007: 49, fig. III.1-4). Se remarca así su carácter ctónico y divino, ya señalado por Blázquez (1955) al citar estos y otros paralelos en su estudio de la pátera de Tivissa. Un carácter que hace posible su relación con ritos de paso o iniciación insistiendo en ese momento en el que el hombre se convierte o se asocia al lobo, en un intento deliberado de asumir su poder (Fogliazza, 2020). Se explica así que en ese mundo etrusco y centro-itálico, más allá del sentido escatológico, el lobo sea el protagonista de una serie de cultos de carácter iniciático, entre los que se puede destacar el de los Hirpi Sorani (Rissanen, 2012; Fogliazza, 2020: 97). En relación con este mundo litúrgico itálico cabe citar una serie de representaciones en bronce y piedra en las que figura un ser mitad hombre-mitad lobo, quizá un sacerdote o chamán ataviado como tal, que es dominado por un grupo de guerreros (Elliot, 1995; Rissanen, 2012: 130-133).

Todo esto parece indicar que el lobo se configura como un animal de poder en el ámbito mediterráneo, adquiriendo un valor simbólico propio que quizá pudo influir en su concepción dentro del propio imaginario ibérico. No obstante, hay que considerar que a diferencia del león, el lobo es un animal que estaba presente en la península, es decir, las sociedades ibéricas convivieron con él, de modo que su caracterización simbólica emanaría de su propio acercamiento al mismo y no necesariamente, al menos en primer grado, de su relación o contacto con estos agentes foráneos.
No es de extrañar por tanto la presencia del mismo en el vaso calado aquí tratado, ya que se trata de una de las especies más representadas dentro de la plástica ibérica en diversos formatos y soportes, como se ha recogido y sintetizado recientemente en trabajos en el marco del proyecto «De lo real a lo imaginario» (p. ej.: Mata y Soria, 2012; Mata et al., 2013: 82; Mata, 2014: 125-130). Estas representaciones se encuentran principalmente en la cerámica (Ramos Folqués y Ramos Fernández, 1990: 161; Conde, 1990; Lillo, 1983; 1988, Pérez Blasco, 2014: 539 y ss.) donde aparece en más de un centenar de ejemplares (Mata, 2014: 126) y en formato escultórico (Chapa, 1979; 1985: 194-204; 1986: 177-182). Está presente también en elementos de adorno personal (Bandera, 1984), destacando las fíbulas argénteas, donde son el animal mayoritario tras el caballo y donde son abundantes los prótomos, pero también en escenas venatorias o enfrentados a héroes y dichos équidos (Angoso y Cuadrado, 1981; Mata et al., 2013: 183-184 y 188-189; Almagro Gorbea et al., 2019: 241-242 con amplia bibliografía). Aparece incluso en los damasquinados de varias falcatas (García Cano y Gómez Ródenas, 2006), rematando los yugos y pasarriendas de carros (Lechuga et al., 2020) e incluso en monedas (Giral, 2006; Mozas, 2006).

Esta ubicuidad, que aquí solo se ha podido recoger de manera sintética ${ }^{5}$, se debe a que el lobo es un fenómeno consustancial a la ideología y a la religiosidad ibérica, pues aparece vinculado a tres ámbitos claros como ya recogieron González y Chapa (1993). El primero de ellos es el funerario, como se puede apreciar en el ya citado kernos de Lorca (García Cano et al., 2016b) y en la caja de Villargordo (Chapa, 1979; 2015) donde se otorga al lobo el papel de animal psicopompo y apotropaico, como un protector del viaje al Más Allá, de la propia tumba y del ajuar del difunto. Según varios autores es, en definitiva, el encargado de llevar el alma del difunto en sus entrañas, de las que resurgirá al alcanzarse el allende (González y Chapa, 1993: 174; Olmos, 1996a: 172; 2011: 120 y ss.; Olmos y Rueda, 2015: 350).

Sin embargo, si se presta atención a los contextos donde aparecen las representaciones de este animal, se observa que el ámbito funerario no es en absoluto el ámbito mayoritario para las mismas, sino que estas son notablemente más numerosas en contextos domésticos (Soria y Mata, 2012; Mata, 2014: 130). Este hecho refleja el segundo de los tres ámbitos definidos por González y Chapa (1993), que no es otro que el valor del lobo como animal emblemático para la aristocracia. El mejor correlato de esta idea, con un añadido valor profiláctico, es quizá el pectoral escultórico con prótomo de lobo de La Alcudia (Elche, Alicante)

\footnotetext{
5. Para profundizar en este repertorio, remitimos a los trabajos ya citados del proyecto «Más allá de lo imaginario» (Mata y Soria, 2012; Mata, 2014: 125) así como a la base de datos del mismo (Flora y Fauna Ibérica, 2009).
} 
(Blanco, 1993; Almagro, 1999; Mata y Soria, 2012: 56). Esta vinculación llega hasta el punto de que el aristócrata se identifica con la fiereza del animal y surge así la metáfora del lobo devorando al carnero, como se puede ver en el conjunto de Cerrillo Blanco de Porcuna (Negueruela, 1990: 258-260).

Paralelamente, en el marco de esta cultura son numerosas las representaciones del joven enfrentándose al lobo (Molinos et al., 1998: 330-334), para las que García Cardiel (2014) ha propuesto una lectura que igualmente refleja el poder del aristócrata. En estas escenas, el humano no se identifica con el animal, sino que imponiéndose a lo salvaje, domina a esta fiera, quizá en un intento deliberado de adquirir sus características, de forma similar a lo que veíamos en el caso etrusco. Por tanto, estas representaciones deben entenderse como una metáfora o alusión a un rito de iniciación o de paso (Olmos, 1996b: 276-277; 1997: 259).

Esto se relaciona directamente con el tercer ámbito iconográfico del lobo, que es el que más interesa aquí, ya que se refiere al papel que este animal desempeña dentro del universo cultual ibérico y que González y Chapa (1993: 172) plasmaron a la perfección, al señalar que:

«Es el animal con el que se identifica al sacerdotechamán y que cumple un papel destacado en los procesos de iniciación. A estos rituales se someten aquellos que desean alcanzar un estatus diferente, más elevado, dentro del grupo social [...]. El lobo conduce al neófito y le somete a unas pruebas que simbolizan su muerte a la vida anterior y su transformación en un hombre nuevo. Una vez cumplido satisfactoriamente, el joven ha vencido al lobo y a lo que representa asumiendo su poder y sus cualidades».

El ejemplo más famoso de estos rituales se documenta quizá en la cueva de La Nariz (Moratalla, Murcia), en la que se ha hallado un fragmento cerámico que representa a una posible divinidad femenina con prótomos de lobo por manos (Lillo, 1983; González y Chapa, 1993: 171), además de un colgante elaborado con un colmillo que tradicionalmente se ha asociado a este animal (Lillo, 1981: 40). Esta vinculación entre dicha cueva y el lobo ha sido puesta en duda recientemente (Ocharan, 2019), señalándose, entre otras cosas, que la diosa no lleva prótomos de lobo sino aves en sus manos o que el colmillo por su morfología y tamaño podría ser de lince. También resultan algo dudosos los restos de lobos hallados en la Cueva del Puntal del Horno Ciego (Villargordo del Cabriel, Valencia) (Sarrión, 1991: 181-182), mal documentado y que pudiera pertenecer a un perro por la cantidad de restos de esta especie allí hallados (Mata, 2014: 125), así como los de la Cueva del Sapo (Chiva, Valencia), que tampoco se han podido adscribir con certeza absoluta al lobo (Machause et al., 2014: 168-169).

En cualquier caso, pese a la pobreza e indefinición del registro faunístico (Mata y Soria, 2012: 53-54; Mata, 2014: 125-126) la vinculación del lobo con los rituales de iniciación aristocrática parece clara en el Mediterráneo en general y en el mundo ibérico en particular. Sin embargo, este sentido cultual o ritual no debe escindirse en ningún caso del carácter aristocrático del animal, un carácter que como hemos dicho explica su mayoritaria aparición en contextos domésticos frente a necrópolis y santuarios. Por el contrario, ambas lecturas están íntimamente relacionadas: como ya se ha esbozado anteriormente y como señalaron González y Chapa (vid. supr.), el aristócrata se identifica y se representa con la figura del lobo porque ha adquirido el poder y la fiereza del animal en el ritual de iniciación, mediante una interacción/enfrentamiento real, o más probablemente, simbólico con el mismo.

Esto es lo que se aprecia claramente en el Vas dels Guerrers de La Serreta (Alcoy, Alicante), donde según Olmos y Grau (2005) se narra la iniciación modélica de un aristócrata o héroe. En la primera escena del vaso, el personaje, caracterizado como un adolescente, se enfrenta al lobo acompañado por la música de una auletris. Lo llamativo es que en la escena que culmina este ciclo iniciático, tras la representación de la caza del ciervo a caballo, aparece el mismo personaje -ya adulto- luchando en un combate singular o ataviado con la piel de lobo (Olmos y Grau, 2005: 92; fig. IX). Es decir, vencer al lobo supone la iniciación y la adopción del animal como tótem para esa nueva identidad guerrera y adulta ${ }^{6}$. Algo similar sobre la asunción iconográfica del lobo fue señalado en cierto modo por Almagro Gorbea (1999: 38) para el caso de La Alcudia. Proponía que allí este era el animal partícipe del rito de iniciación en un linaje o grupo aristocrático guerrero, razón por la que se convirtió en el tótem de toda la aristocracia y, dada la recurrencia de las representaciones, acabó siendo el emblema de la propia ciudad.

Esta relación entre lobo y oppidum, se documenta también en las representaciones monetales, donde esta figura queda emparentada con las narraciones míticas de la ciudad que las emitía (Giral, 2006; Mata y Soria, 2012: 70). Tal vez el caso más paradigmático y conocido al respecto es el del oppidum de Iltiraka (¿Úbeda la Vieja, Jaén?), cuyas emisiones desde el siglo II a. C. incluyen como tipo principal un lobo en posición de ataque e incluso mordiendo algo indeterminado (Mozas, 2006). Según varios autores (Mozas, 2006: 284; Rueda, 2011: 37-38) la elección de este tipo monetal parece indicar que a través de la numismática

\footnotetext{
6. Existen otras representaciones ibéricas de cabezas humanas con la piel de lobo, como se pueden ver en el pasarriendas de la cámara de Piquía (Arjona, Jaén) (Ruiz et al., 2015: 366), el de Maquiz (Mengíbar, Jaén) (Lechuga et al., 2020: 309) o en la pátera de Perotito (Olmos y Rueda, 2015: 350-351). No obstante, como señalan Mata y Soria (2012: 77) no son representaciones habituales en la cultura ibérica y su interpretación resulta ambigua y compleja, aunque a propósito de los bronces de Maquiz, Lechuga et al. (2020: 315) proponían una lectura en clave funeraria y a la par emblemática o aristocrática para estas imágenes.
} 
se rememora y eleva a símbolo de la ciudad el viejo mito protagonizado por este animal que dos siglos antes se había representado en el santuario de El Pajarillo (Huelma, Jaén) ubicado en el territorio o pagus de este Iltiraka.

En definitiva, también en la cultura ibérica, el lobo queda convertido en un animal que oscila entre lo real y lo imaginario (Mata, 2014: 126 y ss.), que se define como un animal de «poder», regio, pero a la vez imbuido de cierto carácter sacro como indica la recurrencia, importancia y variabilidad de sus representaciones. Es una figura que se asociaría por tanto a la divinidad y su universo simbólico e iconográfico, como se aprecia claramente en la cerámica ibérica figurada del sureste peninsular entre los siglos III-I a. C. (Tortosa, 1998: 214), pero sobre todo se vincula a la aristocracia y sus rituales. Un ejemplo de esta asociación simultánea con la aristocracia y lo divino se aprecia claramente en el ya referido «vaso de la diosa» de Libisosa (Uroz Rodríguez y Uroz Saez, 2016; Uroz Rodríguez, 2018: n. ${ }^{\circ}$ 1, 136 y ss.).

Ciertamente, en el ámbito del Mediterráneo Antiguo $y$ en concreto en el ibérico, la imagen del lobo tiene un funcionamiento sumamente complejo, tanto a nivel iconográfico como iconológico. Sin embargo, en los tres ámbitos en los que aparece asociado este animal, tienen como denominador común su concepción como «elemento transformador» o de ser, en palabras de Foglazzia (2020: 96), un animal of passages, es decir, asociado a los procesos de tránsito de un estado a otro.

Este tránsito puede ser el paso de la vida a la muerte, en el que varios autores han puesto énfasis (vid. supr.) para algunas representaciones concretas. Pero sobre todo, puede ser también el paso de la juventud al mundo adulto e incluso, el paso del individuo a un colectivo o grupo social reducido a través de ceremonias rituales de iniciación o pasaje de corte aristocrático. En estas últimas, la figura del lobo adquiere importancia capital y a través de las mismas, el animal se convierte en el emblema del grupo al que se accede.

\section{REFLEXIONES FINALES: SOBRE LA FUN- CIÓN DEL RECIPIENTE}

En definitiva, estamos ante lo que se puede definir como un hápax cerámico dentro de la cultura ibérica: un vaso calado de excelente factura que incorpora en cada una de sus tres patas, pues aunque sólo conservamos dos lo más probable es que la tercera fuese igual, un detallado prótomo de lobo en el que se pueden distinguir los ojos, las orejas y las fauces abiertas, con los dientes representados detalladamente. Como se ha visto existen recipientes plásticos y otros ejemplares que incluyen prótomos modelados de lobo, aunque ninguno de ellos es un vaso calado.

Para esta tipología cerámica se han propuesto tradicionalmente funciones relacionadas con aspectos cultuales debido a su aparición en contextos sacros.
Estas funciones serían la quema de sustancias aromáticas (Molina et al., 1976: 63) o la de servir como posibles foculi o braseros (Mata, 1991: 107; Moneo, 2003: 155 con bibliografía). No obstante, ante la aparición de los mismos en contextos domésticos otros autores propusieron que se trataba de recipientes de cocina destinados a asar frutos como castañas o bellotas (Broncano y Blánquez, 1985: 59; García Cano, 1997: 188) o quizá al transporte de alimentos calientes, como una suerte de hornillo móvil de múltiples usos sobre el que se colocan los recipientes de cocina que contienen el alimento a preparar. Estos «hornillos» cerámicos son conocidos como «anafres» en la alfarería tradicional (Mata, 2019: 117). En este papel doméstico ha insistido recientemente Uroz Rodríguez (2012: 154-155) ante la marcada presencia de estos vasos en contextos habitacionales de Libisosa.

Otra opción señalada por Mata (2019: 117) es el uso de los mismos como punto de iluminación, función que tal vez desempeñó este ejemplar en el entorno de la puerta, algo complicado de asegurar, o tal vez en alguna vivienda del poblado. En cualquier caso, no debe olvidarse que el ejemplar aquí estudiado se contextualiza en el oppidum y no en una necrópolis, por lo que a pesar de la iconografía del lobo y de lo que pudiera sugerir el paralelo lorquí, se debe rechazar su empleo como urna cineraria, pues además el calado de su superficie impediría el correcto recogimiento de las cenizas.

Sin embargo, para este caso concreto consideramos que la función doméstica o cotidiana también puede rechazarse, pues su cuidada factura, la singularidad de sus rasgos morfológicos y sobre todo, la presencia de un animal tan emblemático como el lobo en el mismo son características que le alejan de los «braserillos» o «castañeras» documentados en los otros hábitats referidos e incluso de los ejemplares hallados en este mismo yacimiento (Molina et al., 1976: 63). Todo parece apuntar por tanto a que se trata de un vaso de encargo, vinculado a la aristocracia y más concretamente, a un ámbito ritual o ceremonia en la que este grupo social o una parte del mismo participaba.

Es cierto que la aparición de una pieza de esta entidad en el contexto de la puerta del poblado resulta muy sugerente y podría, a priori, invitar a pensar que este recipiente se integraba en un depósito votivo similar a los hallados en la Bastida de Les Alcusses (VivesFerrándiz et al., 2015) o el faunístico de El Molón (Camporrobles, Valencia) (Lorrio et al., 2014), tras haber jugado algún papel en una liturgia quizá de amortización de la vieja puerta y/o de consagración de la nueva. No obstante, como se ha repasado anteriormente la estratigrafía es bastante clara en esta ocasión, pues el vaso se encontraba fragmentado sobre el suelo de tierra batida del acceso cuando se produjo el derrumbe de la torre y las demás estructuras de la puerta. Además, como se ha adelantado en dicha descripción estratigráfica, hasta la fecha y a pesar de que se ha excavado íntegramente el pasillo de entrada y parte del área septentrional de la acceso hasta el nivel de uso del siglo III 
a. C. no se ha documentado ningún indicio de depósito votivo que se pueda relacionar con la puerta. De hecho, dadas las características de este sector, ni siquiera se puede garantizar que el vaso estuviera en origen situado en el entorno del acceso y no hubiera rodado desde el interior del poblado, como es el caso de numerosos materiales aquí hallados y como parece altamente probable para el recipiente que nos ocupa.

Así pues, el desconocimiento del contexto original del vaso complica bastante precisar el tipo de ritual en el que se empleó y la función concreta que desempeñó en el mismo, algo que solo se puede discernir a partir de la propia morfología del recipiente y sobre todo, a partir de la iconografía del lobo.

Como hemos visto, este es un animal predominante en ámbitos aristocráticos y rituales, donde se vincula directamente a ceremonias de iniciación y/o de paso (González y Chapa, 1993: 173; Almagro Gorbea, 1997; Amorós, 2019: 18-19), en las que este vaso pudo funcionar como quemaperfumes, algo bastante plausible dadas sus dimensiones y los triángulos calados, o incluso como braserillo. Sin embargo, hay que tener en cuenta que su reducido diámetro no permitiría la preparación de grandes cantidades de alimento, como sí que permiten otros ejemplares de esta tipología cerámica (Mata, 2019: fig. 4.73); es decir, si aceptamos esta función de «hornillo» dentro de un contexto ritual, este vaso no se emplearía para cocinar alimentos al uso, sino para preparar alguna sustancia, fruto o alimento muy concreto cuyo consumo formaría parte del propio acto litúrgico.

Este tipo de ceremonias se llevarían a cabo en alguna estancia del poblado, que aún no se ha documentado, o más probablemente fuera de sus murallas, en el entorno inmediato de este oppidum quizá en relación con el santuario, pues aunque aquí no se dé el caso, en otros espacios cultuales de naturaleza y cronología análoga como el de El Recuesto (Cehegín) sí se han documentado estos vasos calados (Lillo, 1980). Incluso, aunque sólo sea una hipótesis difícil de probar por ahora, dada la ya comentada relación del lobo y de los rituales de iniciación con las cuevas-santuario (González y Chapa, 1993: 172; González, 2006; Amorós, 2019: 17 y ss. con amplia bibliografía previa), no resultaría descabellado pensar que este vaso pudiera tratarse de un recipiente litúrgico guardado en el poblado pero relacionado con algún ritual de este tipo que se llevaría a cabo en alguna de las muchas cuevas que existen en la Sierra de Santa Ana y que no han sido exploradas arqueológicamente. Incluso, profundizando en la misma hipótesis, puede proponerse el empleo del recipiente en el banquete que se celebraba como rito de agregación que seguía al de iniciación (Amorós, 2019: 42), pero siempre con ese carácter de perfumar, preparar sustancias concretas e incluso iluminar la estancia.

Independientemente de la función que desempeñó, sobre la que ahora mismo sólo podemos teorizar, ha de tenerse en cuenta que la mayoría de vasos plásticos o con apliques de este tipo establecen juegos visuales con el usuario, a menudo relacionados con el simbolismo de la figura representada. El ejemplo más evidente es quizá el de los askoi ornitomorfos en los que el orificio de vertido del líquido coincide con el pico del animal, de modo que al usarse parece ser el ave el que escupe o derrama la sustancia contenida en su interior.

En este caso, creemos que pudo existir también un juego visual, aunque actualmente este debe entenderse como una sugerente hipótesis que en un futuro se podrá comprobar con cierta facilidad gracias a la Arqueología Experimental. Para considerar esta propuesta hay que tener en cuenta el tamaño de los prótomos, pues aunque pudieran parecer reducidos no lo son en proporción con el vaso, ocupando la mitad de su altura. Del mismo modo, es necesario prestar atención a su ubicación en el recipiente: se orientan hacia arriba, situándose en torno a la superficie calada, punto de emanación de luz y de los posibles vapores de las sustancias que ardían dentro. Por tanto, el juego visual se originaría al contener el vaso brasas incandescentes, lo que provocaría que el usuario contemplase, quizá en la penumbra de un espacio ritual como pudiera ser una cueva, tres cabezas de lobos de grandes ojos y marcadas fauces que, al estar orientadas hacia arriba, le mirarían directamente como acechando entre el humo que saldría por los triángulos calados.

\section{REFERENCIAS}

Adroher, A. M. (2018). Los santuarios ibéricos. El modelo de Coimbra del Barranco Ancho. En R. M. Gualda Bernal y E. Hernández Carrión (Eds.). El legado de Jerónimo Molina a la Arqueología. Actas del congreso (Jumilla, 2013) (pp. 65-88). Murcia: Centro de Estudios del Próximo Oriente y la Antigüedad Tardía.

Almagro Gorbea, M. (1997). Lobos y ritos de iniciación en Iberia. En R. Olmos y J. A. Santos Velasco (Eds.). Iconografía ibérica, iconografía itálica. Propuestas de interpretación y lectura (pp. 103-128). Madrid: Universidad Autónoma de Madrid.

Almagro Gorbea, M. (1999). El rey lobo de la Alcudia. Alicante: Museo de la Universidad de Alicante.

Almagro Gorbea, M., Ballester, X., Roura, M. A. y Turiel, M. (2019). Tesera celtibérica en forma de cierva procedente de Burgo de Osma (Soria España). Cuadernos de Prehistoria y Arqueología de la Universidad Autónoma de Madrid, 45, 239248. DOI: https://doi.org/10.15366/cupauam2019.45.009

Amorós, I. (2019). Ideología, poder y ritual en el paisaje ibérico: procesos sociales y prácticas rituales en el área central de la Contestania. Valencia: Servicio de Investigaciones Prehistóricas.

Angoso, C. y Cuadrado, E. (1981). Fíbulas ibéricas con escenas venatorias. Boletín de la Asociación Española de Amigos de la Arqueología, 13, 18-30.

Bandera, M. L. de la (1984). Brazaletes peninsulares orientalizantes e ibéricos en metales nobles. Habis, 15, 365-418. 
Blanco Freijeiro, A. (1993). El carnassier de Elche. En Homenaje a Alejandro Ramos Folqués: ciclo de conferencias desarrollado en Elche entre los días 25 y 29 de noviembre de 1985 (pp. 82-97). Elche: Caja de Ahorros del Mediterráneo.

Blázquez, J. M. (1955-1956). La interpretación de la pátera de Tivisa. Ampurias, 17-18, 111-140.

Bonet, H. (1995). El Tossal de Sant Miquel de Llíria. La antigua Edeta y su territorio. Valencia: Diputación provincial.

Bonet, H. y Mata, C. (2017). Verdadero o Falso. Deshojando la margarita. En F. Arrasa i Gil y C. Mata (Eds.). Homenaje a la Profesora Carmen Aranegui Gascó (pp. 127-140). Saguntum Extra, 19. Valencia: Universitat de València. Recuperado de: https://roderic.uv.es/handle/10550/58634?show=full

Broncano, S. y Blánquez, J. J. (1985). El Amarejo (Bonete, Albacete). Madrid: Subdirección General de Arqueología y Etnografía.

Broncano, S. (1989). El depósito votivo ibérico de El Amarejo. Bonete (Albacete). Excavaciones Arqueológicas en España, 156. Madrid: Ministerio de Cultura.

Buxton, R. (2013). Myths and Tragedies in their Ancient Greek Contexts. Oxford: Oxford University Press. DOI: https://doi. org/10.1093/acprof:oso/9780199557615.001.0001

Cárceles, E., Gallardo Carrillo, F. González Ballesteros, J. A. y Ramos Martínez, F. (2008). La necrópolis ibérica de Lorca. Una visión de conjunto. En J. Blánquez y A. Adroher (Eds.). Ier Congreso Internacional de Arqueología Ibérica Bastetana. Comunicaciones (pp. 43-58). Serie Varia, 9. Madrid: UAM Ediciones.

Chapa, T. (1979). La caja funeraria de Villargordo (Jaén). Trabajos de Prehistoria, 36(1), 445-458.

Chapa, T. (1985). La escultura ibérica zoomorfa. Madrid: Ministerio de Cultura.

Chapa, T. (1986). Influjos griegos en la escultura zoomorfa ibérica. Madrid: Consejo Superior de Investigaciones Científicas.

Chapa, T. (2015). La caja funeraria de Villargordo. En A. Ruiz y M. Molinos (Coords.). Jaén, tierra íbera: 40 años de investigación y transferencia (pp. 297-304). Jaén: Universidad de Jaén.

Comino, A. (2015). El santuario ibérico de La Luz (Santo Ángel, Murcia) como elemento de identidad territorial (s. IV/III a. C.-I d. C.). (Tesis doctoral). Universidad de Murcia. Murcia. Recuperado de: https://digitum.um.es/digitum/ handle/10201/48130

Conde, M. (1990). Los kalathoi «sombrero de copa» de la Necrópolis del Cabecico del Tesoro de Verdolay (Murcia). Verdolay, 2, 149-160.

Cuadrado, E. (1987). La necrópolis ibérica de «El Cigarralejo» (Mula, Murcia). Bibliotheca Praehistorica Hispana, 23. Madrid: Consejo Superior de Investigaciones Científicas.

Elliot, J. (1991). The Mask in Etruscan Religion, Ritual and Theater. Florida: Florida State University.
Elliott, J. (1995). The Etruscan Wolfman in Myth and Ritual. Etruscan Studies, 2, 17-31. DOI: https://doi.org/10.1515/ etst.1995.2.1.17

Ferrer, J. y Escrivá, V. (2013). Quatre noves inscripcions ibèriques pintades procedents de Llíria. Palaeohispanica, 13, 461-482.

Ferrer, J. y Escrivá, V. (2018). Estudio epigráfico de la inscripción ibérica de la tinajilla de la Fundación Ballesta, ya conocida por un dibujo y dos falsificaciones. Palaeohispanica, 18, 171-187.

Fletcher, D., Pla, E. y Alcácer, J. (1969). La Bastida de les Alcusses II (Mogente-Valencia). Valencia: Diputación Provincial de Valencia.

Flora y Fauna Ibérica. (2009) Base de datos Flora y Fauna Ibérica: de lo real a lo imaginario. [Base de datos]. Recuperado de: http://www.florayfaunaiberica.org/

Foglazzia, S. (2020). Wolves and Gods in the etruscan world. Acta Musei Tiberiopolitani, 3, 95-102.

Gallardo Carrillo, J., García Cano, J. M., Hernández Carrión, E. y Ramos Martínez, F. (2017). Excavaciones en Coimbra del Barranco Ancho, Jumilla 2015-2016. Murcia: Centro de Estudios del Próximo Oriente y la Antigüedad Tardía.

García Cano, J. M. (1997). Las necrópolis ibéricas de Coimbra del Barranco Ancho (Jumilla, Murcia). I. Las excavaciones y estudio analítico de los materiales. Murcia: Universidad de Murcia. DOI: https://doi.org/10.21071/aac. v0i.11333

García Cano, J. M., Fenoll Cascales, J., Robles, J., Gallardo, J., Hernández, E. y Ramos, F. (e.p.). Memoria de las excavaciones en Coimbra del Barranco Ancho (Jumilla, Murcia). Las investigaciones arqueológicas en el Poblado 1977-2019. Manuscrito en preparación. Murcia.

García Cano, J. M., Gallardo Carrillo, J., Ramos Martínez, F., Martínez García, J. J., Hernández Carrión, E., Gualda Bernal, R. y Crespo Valero, J. M. (2016a). Plan Director del conjunto arqueológico Coimbra del Barranco Ancho. Murcia: Centro de Estudios del Próximo Oriente y la Antigüedad Tardía.

García Cano, J. M. y Gómez Ródenas, M. (2006). Avance al estudio radiológico del armamento de la necrópolis ibérica de Cabecico del Tesoro (Verdolay, Murcia). I. Las falcatas, Gladius, 26, 61-92. DOI: https://doi.org/10.3989/gladius.2006

García Cano, J. M., Hernández Carrión, E., Iniesta Sanmartín, Á. y Page del Pozo, V. (1997). El santuario de Coimbra del Barranco Ancho (Jumilla, Murcia) a la luz de los nuevos hallazgos. Quaderns de Prehistòria i Arqueologia de Castelló, 18, 239-256.

García Cano, J. M., Iniesta, A. y Page del Pozo, V. (19911992). El santuario ibérico de Coimbra del Barranco Ancho (Jumilla, Murcia). Anales de Prehistoria y Arqueología, 7-8, $75-82$.

García Cano, J. M. y Page Del Pozo, V. (1983). Un nuevo relieve zoomorfo procedente de Osuna (Sevilla). En Crónica del XVI Congreso Arqueológico Nacional (pp. 789-794). Zaragoza: Universidad de Zaragoza. 
García Cano, J. M. y Page Del Pozo, V. (2004). Terracotas y vasos plásticos de la necrópolis del Cabecico del Tesoro, Verdolay, Murcia. Mula: Museo de Arte Ibérico de El Cigarralejo.

García Cano, J. M. y Page Del Pozo, V. (2007). 30 años de investigaciones en Coimbra del Barranco Ancho, Jumilla. Catálogo de la exposición. Murcia: Museo de la Universidad de Murcia - Museo Arqueológico Municipal Jerónimo Molina.

García Cano, J. M., Ramos Martínez, F., Gallardo Carrillo, J. y Cárceles López, E. (2016b). Novedades en el ritual funerario ibérico. El kernos de la necrópolis de Lorca (Murcia). Alberca, 14, 71-89.

García Cardiel, J. (2014). El combate contra el mal: imaginarios locales de poder a través de la conquista romana en el levante ibérico. Complutum, 25(1), 159-175. DOI: https:// doi.org/10.5209/rev CMPL.2014.v25.n1.45361

Giral Royo, F., 2006, El lobo en las acuñaciones de «Iltirta» imagen monetaria de un mito. Pyrenae 37(2), 71-82.

González Alcalde, J. (2006). Totemismo del lobo, rituales de iniciación y cuevas-santuario mediterráneas e ibéricas. Ouaderns de prehistòria i arqueologia de Castelló, 25, 249-269.

González Alcalde, J. y Chapa, T. (1993) Meterse en la boca del lobo. Una aproximación a la imagen del «carnassier» en la religión ibérica. Complutum, 4, 169-174.

Lechuga, M. A., Rueda, C. y Bellón, J. P. (2020). Los «Bronces de Maquiz». Nuevas propuestas para su contextualización dentro del proceso histórico de Iliturgi. Complutum, 31(2), 305-324. DOI: https://doi.org/10.5209/cmpl.72486

Lillo, P. A. (1980). Las religiones indígenas de la Hispania antigua en el Sureste Peninsular. El santuario del Recuesto (Cehegín). Anales de la Universidad de Murcia, 38(4), 196-213.

Lillo, P. A. (1981), El poblamiento ibérico en Murcia. Murcia: Universidad de Murcia - Academia Alfonso X El Sabio.

Lillo, P. A. (1983). Una aportación al estudio de la Religión Ibérica: La Diosa de los Lobos de la Umbría de Salchite, Moratalla (Murcia). En XVI Congreso Arqueológico Nacional (pp. 769-788). Zaragoza: Universidad de Zaragoza.

Lillo, P. A. (1988). Una pareja de lobos en la cerámica pintada ibérica. Anales de Prehistoria y Arqueología, 4, 137-147.

Lorrio, A., Iborra, M. P. y Sánchez de Prado, M. ${ }^{a}$ D. (2014). Depósitos rituales de fauna en el oppidum prerromano de El Molón (Camporrobles, Valencia). Archivo de Prehistoria Levantina, 30, 213-238.

Machause, S., Pérez, A., Vidal, P. y Sanchis, A. (2014): Prácticas rituales en la Cueva del Sapo (Chiva, Valencia): Más allá del Caliciforme. Zephyrvs, 74, 157-179. DOI: https://doi. org/10.14201/zephyrus201474157179

Mata, C. (1991). Los Villares (Caudete de las Fuentes, Valencia). Origen y evolución de la Cultura Ibérica. Serie de Trabajos Varios del SIP, 88. Valencia: Servicio de Investigación Prehistórica.
Mata, C., Bonet, H., Collado, E., Fuentes, M., Izquierdo, I., Moreno, A.,... y Tormo, C. (2013): Fíbulas y género, de animales y hombres en la cultura Ibérica. Zephyrus, 71, 173-195.

Mata, C. y Soria, L. (2012). ¡Qué viene el lobo!. De lo real a lo imaginario: aproximación a la fauna ibérica de la Edad del Hierro. En M. R. García Huerta y F. Ruiz Gómez (Eds.). Animales simbólicos en la historia. Desde la Protohistoria hasta el final de la Edad Media (pp. 47-78). Madrid: Síntesis.

Mata, C. (Coord.). (2014). Fauna Ibérica. De lo real a lo imaginario II. Madrid: Consejo Superior de Investigaciones Científicas.

Mata, C. (2019): De Kelin a los Villares (Caudete de las Fuentes, Valencia). Nacimiento y decadencia de una ciudad ibera. Serie de Trabajos Varios del SIP, 122 Valencia: Servicio de Investigación Prehistórica.

Molinos, M., Chapa, T., Ruiz, A., Pereira, J., Rísquez, C., Madrigal, A.,... y Mayoral, V. (1998). El santuario heroico de «El Pajarillo». Huelma (Jaén). Jaén: Universidad de Jaén.

Moneo, T. (2003). Religio iberica. Santuarios, ritos y divinidades (siglos VII-I a. C.). Bibliotheca Archaeologica Hispana, 20. Real Academia de la Historia, Madrid.

Moore, K. (2016). Pythagoras and the (Were)Wolf. Athens Journal of History, 4, 227-238. DOI: https://doi.org/10.30958/ ajhis.2-4-1

Moreno, D. y Adroher, A. M. (2019). Piezas discoidales recortadas en cerámica: perspectiva desde un depósito íbero de Iliberri (Granada). Zephyrus, 84, 63-88. DOI: https://doi. org/10.14201/zephyrus2019846388

Mozas, M. S. (2006). Consideraciones sobre las emisiones de «Iltiraka». En Actas del XII Congreso Nacional de Numismática (pp. 269-286). Madrid: Real Casa de la Moneda, Fábrica Nacional de Moneda y Timbre.

Negueruela, I. (1990). Los monumentos escultóricos ibéricos del Cerrillo Blanco de Porcuna (Jaén). Estudio sobre su estructura interna, agrupamientos e interpretación. Madrid: Ministerio de Cultura.

Obermaier, H. y Heiss, C. W. (1929). Iberische Prunk-Keramik vom Elche-Archena-Typus. Jahrbuch für Prähistorische und Etnographische Kunst 1929, 56-73.

Ocharan, J. A. (2017). Santuarios rupestres ibéricos del sureste peninsular. (Tesis doctoral). Universidad de Alicante. Alicante. Recuperado de: http://hdl.handle.net/10045/74633

Ocharan, J. A. (2019): La diosa de Salchite. Estudio e interpretación iconográfica del fragmento procedente del santuario rupestre ibérico de La Nariz (Moratalla, Murcia). Espacio, Tiempo y forma. Serie I: Prehistoria y Arqueología, 12, 67-95. DOI: https://doi.org/10.5944/etfi.12.2019.23070

Olmos, R. (1996a). Caminos escondidos. Imaginarios del espacio en la muerte ibérica. En M. ${ }^{\mathrm{a}}$ A. Querol Fernández y M. ${ }^{\text {a }}$ T. Chapa Brunet (Coords.). Homenaje al profesor Manuel Fernández-Miranda, II (pp. 167-176). Complutum Extra 6, II. Madrid: Universidad Complutense de Madrid. Recuperado de: https://revistas.ucm.es/index.php/CMPL/ article/view/CMPL9696330167A/29831 
Olmos, R., (1996b). La representación humana en la cerámica del sureste: símbolo y narración. En XXIII Congreso Nacional de Arqueología (pp. 275-282). Zaragoza: Universidad de Zaragoza.

Olmos, R. (1997). Juegos de imagen, relato y poder en el Mediterráneo antiguo. Ejemplos ibéricos. En A. Domínguez Monedero y C. Sánchez Fernández (Eds.). Arte y poder en el Mundo Antiguo. Madrid: Ediciones Clásicas - UAM Ediciones

Olmos, R. (2011). En los umbrales de la muerte. Itinerarios del Más Allá en la imagen ibérica. En J. Blánquez (Ed.). ¿Hombres o dioses? Una nueva mirada a la escultura del Mundo Ibérico (pp. 107-129). Madrid: Museo Arqueológico Regional.

Olmos, R. y Grau, I. (2005). El Vas dels Guerrers de La Serreta. Recerques del Museu d'Alcoi, 14, 79-98.

Olmos, R. y Rueda, C. (2015). La Pátera de Perotito (Santisteban del Puerto, Jaén). En A. Ruiz y M. Molinos (Coords.). Jaén, tierra íbera: 40 años de investigación y transferencia (pp. 339-356). Jaén: Universidad de Jaén.

Pla Ballester, E. (1980). Los Villares (Caudete de las Fuentes). Serie de Trabajos Varios del SIP, 68. Valencia: Servicio de Investigación Prehistórica.

Pérez Blasco, M. (2014). Cerámicas ibéricas figuradas (siglos V-I a. C.). Iconografía e Iconología. (Tesis doctoral). Universidad de Alicante. Alicante. Recuperado de: http://hdl. handle.net/10045/41124

Rafel Fontanals, N., Jornet Niella, F. y Burillo-Cuadrado, P. (2018). Una vasija decorada ibérica de función ceremonial: un espacio singular en el Coll del Moro (Gandesa, Tarragona). Complutum, 29(1), 135-150. DOI: https://doi. org/10.5209/CMPL.62399

Ramos Fernández, R. (1987). Iconografía funeraria en algunas cerámicas de La Alcudia. Archivo Español de Arqueología, 60, 231-236.

Ramos Folqués, A. y Ramos Fernández, R. (1990). Cerámica ibérica de La Alcudia (Elche - Alicante). Alicante: Diputación Provincial de Alicante, Instituto Alicantino de Cultura Juan Gil-Albert.

Richardson, E. H. (1977). The Wolf in the West. Journal of the Walters'Art Gallery, 36, 91-101.

Rissanen, M. (2012). The Hirpi Sorani and the wolf cults of Central Italy. Arctos, 46, 115-135.

Rueda, C. (2011). Territorio, culto e iconografía en los santuarios iberos del Alto Guadalquivir (siglos IV a.N.E - II d.N.E.). Jaén: Universidad de Jaén.

Ruiz, A., Molinos, M., Rísquez, C., Gómez, F. y Lechuga, M. A. (2015): La cámara de Piquía, Arjona. En A. Ruiz y M. Molinos (Coords.). Jaén, tierra ibera: 40 años de investigación y transferencia (pp. 357-374). Jaén: Universidad de Jaén.
Rupp, W.L. (2007). Shape of the Beast: The Theriomorphic and Therianthropic Deities and Demons of Ancient Italy (Tesis doctoral). Florida: Florida State University. Recuperado de: http://purl.flvc.org/fsu/fd/FSU migr etd-1937

Sánchez Gómez, E. (2002). El santuario de El Cerro de los Santos (Montealegre del Castillo, Albacete). Nuevas aportaciones arqueológicas. Albacete: Instituto de Estudios Albacetenses.

Sarrión, I. (1990). Estudio de la fauna de la Cueva II. Saguntum, 23, 181-182.

Tortosa, T. (1998). Los grupos pictóricos en la cerámica del Sureste y su vinculación al denominado estilo Elche-Archena. En C. Aranegui (Ed.). Actas del Congreso Internacional: Los Iberos, príncipes de Occidente (Barcelona, Marzo 12-14, 1998) (pp. 207-217). Valencia: Universidad de Valencia.

Tortosa, T. (2006). Los estilos y grupos pictóricos de la cerámica ibérica figurada en la "Contestania». Mérida: Instituto de Arqueología de Mérida.

Uroz Rodríguez, H. (2007). El carnassier alado en la cerámica ibérica del Sudeste. Verdolay, 10, 63-82.

Uroz Rodríguez, H. (2009). Los íberos de Elda. El poder de las imágenes, las imágenes del poder. En Elda. Arqueología y Museo. Ciclo Museos Municipales en el MARQ (pp. 60-77). Alicante: Museo Arqueológico Regional.

Uroz Rodríguez, H. (2012). Prácticas rituales, iconografía vascular y cultura material en Libisosa (Lezuza, Albacete). Nuevas aportaciones al Ibérico final del Sudeste. Alicante: Universidad de Alicante.

Uroz Rodríguez, H. (2013). Héroes, guerreros, caballeros, oligarcas: tres nuevos vasos singulares ibéricos procedentes de Libisosa. Archivo Español de Arqueología, 86, 51-73. DOI: https://doi.org/10.3989/aespa.086.013.004

Uroz Rodríguez, H. (2018). Más que objetos rituales: Un nuevo conjunto de vasos plásticos. Saguntum, 50, 129-163. DOI: https://doi.org/10.7203/SAGVNTVM.50.10933

Uroz Rodríguez, H. y Uroz Sáez, J. (2014). La «Libisosa» iberorromana: un contexto cerrado de, y por, las guerras sertorianas. En F. Sala Sellés y J. Moratalla (Eds.). Las guerras civiles romanas en Hispania. Una revisión histórica desde la Contestania (pp. 199-215). Alicante: Universidad de Alicante - Museo Arqueológico de Alicante.

Uroz Rodríguez, H. y Uroz Sáez, J. (2016). Imagen divina, vaso ritual, mito aristocrático. La diosa y el príncipe ibero de Libisosa. En V. Gasparini (Coord.). Vestigia. Miscellanea di studi storico-religiosi in onore di Filippo Coarelli nel suo $80^{\circ}$ anniversario (pp. 281-294). Stuttgart: Franz Steiner Verlag.

Vives-Ferrándiz, J., Bonet Rosado, H., Carrión Marco, Y., Ferrer García, C., Iborra Eres, P., Pérez Jordà, G.,... y Tortajada Comeche, G. (2015). Ofrendas para una entrada: un depósito ritual en la Puerta Oeste de la Bastida de les Alcusses (Moixent, Valencia). Trabajos de Prehistoria, 72, 282-303. DOI: https://doi.org/10.3989/tp.2015.12155 